\title{
4. Literarische Entgrenzungsversuche im Zeichen des Monismus
}

Die zunächst nur von den Naturalisten propagierte "Szientifizierung der Kunst« ${ }^{1}$ fand seit der lebensphilosophischen Wende Anfang der neunziger Jahre mit einem Mal auch Anhänger außerhalb dieser literarischen Formation. Daß Schriftsteller ihre Ästhetik plötzlich auf breiter Front durch wissenschaftliche Aussagen abzustützen versuchten, ist zwar im allgemeinen durchaus dem Legitimationsdruck zuzuschreiben, dem sich die Künste generell ausgesetzt sahen, resultiert im besonderen aber wohl aus der veränderten Struktur naturkundlicher Forschung. Besonders die Naturwissenschaften hatten sich nämlich erkennbar vom Ideal experimentell gewonnenen Faktenwissens entfernt und statt dessen mehr und mehr spekulative Züge angenommen. Exakte Wissenschaft amalgamierte sich mit traditionellen Formen der $\mathrm{Na}$ turphilosophie, ${ }^{2}$ und dieses vergröberte Konglomerat wiederum wurde von zahlreichen, wohlmeinenden - allerdings meist nur halbgebildeten - Multiplikatoren für den Alltagsgebrauch aufbereitet. So entstand eine leicht rezipierbare Populärwissenschaft, deren Thesen von den meisten Zeitgenossen gleichwohl als gesicherte Erkenntnisse genommen wurden und deshalb eine ungeheure Breitenwirkung erlebten. $^{3}$

Die beiden beliebtesten Deutungsmodelle der Jahrhundertwende waren dabei die auf Charles Darwin zurückgehende Abstammungslehre in ihrer doppelten Ausprägung als nietzeanisch (Wille zur Macht) verstandene Theorie des Kampfes ums Überleben und als umfassendes evolutionäres Entwicklungsparadigma im Sinne Ernst Haeckels sowie das vor allem auf Gustav Theodor Fechner und ebenfalls Haeckel beruhende Konzept des psychophysischen Monismus. Während ersteres

1 Dieter Borchmeyer: Der Naturalismus und seine Ausläufer, S. 166.

2 Scheuer hat mit Recht darauf hingewiesen, daß es mum 1900 [...] eine Fülle von Versuchen gibt, "mystische Naturphilosophien und exakte Naturwissenschaften miteinander zu verbinden«; Helmut Scheuer: Amo Holz' "Wende einer Zeit in Dramenж. Vom Milieustück zum Seelendrama. In: Text + Kritik. Zeitschrift für Literatur. Bd. 121: Amo Holz. München: edition text + kritik 1994, S. 59f. Siehe in diesem Zusammenhang auch H. S.: Naturalismus und Naturwissenschaft.

3 Vgl. hierzu etwa Wolfgang Riedel: „Homo Naturaw. Literarische Anthropologie um 1900. Berlin/New York: de Gruyter 1996 (= Quellen und Forschungen zur Literatur- und Kulturgeschichte 7), S. 62-84. 
die Literatur vor allem inhaltlich prägte, hatte letzteres unmittelbare Rückwirkungen auf die Ästhetik selbst. Der Grund dafür ist leicht einzusehen: Da nach monistischer Überzeugung die gesamte materielle Welt mitsamt ihren kleinsten Bestandteilen, den Atomen, als belebt, ja beseeltr gedacht werden muß, gelingt es auf diese Weise, die von Descartes installierte neuzeitliche Spaltung des Seins in Körper und Geist rückgängig zu machen bzw. zu umgehen, weil Materielles und Geistiges nunmehr als zwei verschiedene Erscheinungsformen einer vitalistisch verstandenen Grundsubstanz aufgefaßt werden. Wie Monika Fick gezeigt hat, kam der vom Monismus versprochene "Kompromiß zwischen der materialistischen Naturwissenschaft und den Forderungen des Geistes« »einem zentralen Bedürfnis der Zeit» ${ }^{4}$ entgegen. Denn der Grundsatz des psychophysischen Parallelismus, der besagt,

[...] daß überall und generell dem materiellen Erscheinungszusammenhang ein geistiger entsprechen müsse, erlaubte es, einerseits das Weltbild im Sinne der modemen Naturwissenschaften weiter auszubauen, andererseits ein unabhängiges Reich des Geistes zu behaupten [...]: Der psychophysiologische Monismus gibt das Vertrauen in die Sinnenwelt zurück. [...] Weniger als Bewußtseinsphänomen denn vielmehr als - sinnliches - Erlebnisphänomen gestaltet sich demnach die Außenwelt ${ }^{5}$.

Weil sein Bestreben vor allem darauf gerichtet ist, wmit den Sinnen das Ding an sich « »zu erkennen " ${ }^{6}$, dreht sich in diesem Theoriegebäude alles um eine "Versinnlichung des Geistigen ${ }^{7}$ - eine Aufgabe, welche die Ästhetik seit jeher als die ihre begriffen hat. Und so kann es denn auch kaum verwundern, wenn monistische Konzepte vielfach Eingang in die Poetiken zeitgenössischer Autoren fanden.

4 Monika Fick: Sinnenwelt und Weltseele. Der psychophysische Monismus in der Literatur der Jahrhundertwende. Tübingen: Niemeyer 1993 (= Studien zur deutschen Literatur 125), S. 50. Unverständlicherweise wird Dauthendey in Ficks Darstellung an keiner Stelle erwähnt.

5 Ebd., S. 49 und 68. Bayertz spricht in diesem Zusammenhang von der vitalistischen "Wiederverzauberung der Weltc; Kurt Bayertz: Die Deszendenz des Schönen. Darwinisierende Ästhetik im Ausgang des 19. Jahrhunderts. In: Fin de siècle. Zu Naturwissenschaft und Literatur der Jahrhundertwende im deutsch-skandinavischen Kontext. Vorträge des Kolloquiums am 3. und 4. Mai 1984. Hrsg. von Klaus Bohnen, Uffe Hansen und Friedrich Schmöe. Kopenhagen/München: Fink 1983 (= Text \& Kontext. Sonderreihe 20), S. 99.

6 Monika Fick: Sinnenwelt und Weltseele. Der psychophysische Monismus in der Literatur der Jahrhundertwende, S. 155. Dies bedeutet zugleich einen Sprung zurück hinter Kants Transzendentalphilosophie, die das 'Ding an sich kategorial von seiner IErscheinung getrennt und damit die neuzeitliche Subjekt/Objekt-Spaltung endgültig etabliert hatte. Ebd., S. 354. Schon 1890 hatte Hermann Bahr in seinem Aufsatz Die Moderme als Leitziel der neuesten Kunst formuliert: "Ja, nur den Sinnen wollen wir uns vertrauen, was sie verkündigen und befehlen. Sie sind die Boten von draußen, wo in der Wahrheit das Glück ist. Ihnen wollen wir dienen.« Hermann Bahr: Zur Überwindung des Naturalismus. Theoretische Schriften 1887-1904, S. 36. 


\section{a. Überwindung der Gattungstrias durch Entmimetisierung der Dichtungssprache: Max Dauthendeys Ultra Violett}

Die Ästhetik Max Dauthendeys (1867-1918) hat ihren Ausgangspunkt in einer für die damalige Zeit typischen Krisenerfahrung. Wie viele Intellektuelle erlebte auch Dauthendey die stürmisch um sich greifende Technisierung der Lebenswelt in Kombination mit einer ständig dominanter werdenden Naturwissenschaft, welche die Deutungskompetenz für immer weitere Bereiche der Erfahrungswirklichkeit beanspruchte, als einen Prozeß, der die Literatur, vor allem aber die sPoesier in ein fast aussichtslos erscheinendes Rückzugsfecht zu verwickeln drohte. Der debütierende Schriftsteller zog daraus zunächst die Konsequenz, auf sDichtung im herkömmlichen Sinne zu verzichten. In seinen Memoiren Gedankengut aus meinen Wanderjabren berichtet er darüber rückblickend:

Durch die neue Weltanschauung war ich aus dem Gleichgewicht der griechischen Rhythmen und einlullenden gutmütigen Melodien der alten Dichterwelt aufgerüttelt worden, und die Trochäen und die Jamben und der Hexameter, alle die uns von den Griechen überkommenen Versmaße, schienen mir undeutsch, zu feierlich und nicht auf die heutigen Lebensäußerungen und Lebenszerrissenheiten anwendbax, mit denen der Arbeitsgeist uns Menschen einer neuen Welt umgibt. [...] Nach dieser Erkenntnis war es mir vorerst unmöglich, daran zu denken, Gedichte zu schreiben, da ich nicht im alten Versmaß schreiben wollte und zur Eingebung des neuen noch nicht gekommen war. [...]

Und so stellte ich mich auf den Standpunkt, daß es vorläufig unmöglich sei, Gedichte zu schreiben in einer Zeit, die voll Maschinenlärm und Reiselärm war und mit Trumphen und neuen Wahrheiten der Naturwissenschaft protzte.

Ich wollte mich deshalb zuerst nur in einer neuen Erzählerkunst ausbilden, ausgehend von haarscharfster [sic] Beobachtung und genauester Wiedergabe der zartesten Lebenseindrücke. $[\ldots]$

[...] Dichtung schien mir, war heutzutage nur noch möglich für junge Mädchen, Schüler, ältere Tanten und Greise.

Der zeitgemäße Mann solite auf die altmodische Süßigkeit gedichteter Gedanken verzichten und das Prosawort handhaben lemen und seine Gedanken durch die Kraft einer neuen Prosa vermitteln. - (D-GW I, S. 410-412)

Mit seinem Entschluß, die Prosa der Lyrik vorzuziehen, übernahm Dauthendey einen Lösungsansatz, der im Rahmen der naturalistischen Programmdebatten vorgeschlagen worden war. ${ }^{8}$ Allerdings blieb die ausschließliche Orientierung am "Prosawort« innerhalb seiner Entwicklung zum Autor lediglich ein kurzes und vergleichsweise unbedeutendes Übergangsstadium, gelangte er doch schon sehr bald zu der „Überzeugung, daß der Wunsch, Dichtungen in Versen und Gesängen zu schaffen, trotz des Maschinenzeitalters und trotz der Wirklichkeitskunst [...] nicht unmöglich war" (D-GW I, S. 462). Die damit verbundene konsequente Rückkehr zum Ausdrucksregister der >Poesie markiert zugleich die definitive Abkehr von den ästheti-

8 Vgl. hierzu Kapitel III/2. 
schen Prinzipien des Naturalismus. Gleichwohl restaurierte Dauthendey nicht einfach das herkömmliche System literarischer Textsorten; vielmehr bekannte er sich nachdrücklich zu jenen Erweiterungen des Gattungsspektrums, welche namhafte Autoren im Umkreis des Naturalismus theoretisch vorgeschlagen (Max Halbe) oder praktisch erprobt (Detlev von Liliencron, Otto Julius Bierbaum) hatten. Und ähnlich wie diese leitete er auch seine ästhetischen Grundbegriffe direkt aus naturwissenschaftlich-philosophischen Weltdeutungsmodellen ab.

Bereits in seinen Würzburger Studienjahren (1890/91) war Dauthendey mit den gängigen atomistischen Theorien der Zeit bekannt geworden, ${ }^{9}$ die freilich ein eher mechanistisches Weltbild entwarfen. Der Durchbruch zu einem veränderten Dichtungsverständnis ereignete sich, als er mit dem Gedankengut des Monismus in Berührung kam, wie es in Ernst Haeckels Konzeption einer beseelten Materie, mehr aber noch in Rudolph Hermann Lotzes atomistischem Panpsychismus sowie der von Gustav Theodor Fechner entworfenen und von seinen Adepten Bruno Wille und Wilhelm Bölsche weiterentwickelten Psychophysik charakteristische Ausprägungen fand. ${ }^{10}$ Nun eröffnete sich die Aussicht auf ein neues rganzheitliches, Deu-

9 Entscheidende Anregungen erhielt er durch seinen Freund Arnold Villinger, der u.a. bei dem Würzburger Physiologen Adolf Fick Vorlesungen belegte. Wendt spricht sogar von der natomistic basis« von Dauthendeys Weltanschauung; H.[erman] G.[eorg] Wendt: Max Dauthendey poet-philosopher. New York: Columbia University Press 1936 (= Columbia University Germanic Studies N.S. 2), S. 32.

10 Vgl. Ferdinand Josef Schneider: Max Dauthendey und der modeme Panpsychismus. In: Zeitschrift für Ästhetik und allgerneine Kunstwissenschaft 23 (1929), S. 326-347, und H. [erman] G. [eorg] Wendt: Max Dauthendey poet-philosopher, S. 47 und 57. Mit den beiden Letztgenannten stand er übrigens in persönlichem Kontakt. So berichtet Geiger, daß Dauthendey, als er "Ende des Jahres 1891 nach Berlin « gekommen sei, den "ganzen Friedrichshagener Ring mit Wilhelm Bölsche und Bruno Wille [...] an der Spitzem kennengelemt habe; Hannsludwig Geiger: Es war um die Jahrhundertwende. Gestalten im Banne des Buches: Albert Langen / Georg Müller. München: Langen/Müller 1953, S. 150 und 152. Auf Lotze als Anreger Dauthendeys hat als erster Riedel hingewiesen; vgl. Wolfgang Riedel: "Homo Natura. Literarische Anthropologie um 1900, S. 116f. Schopenhauers und Nietzsches physiologisch akzentuierte Willensmetaphysik spielt in diesem Zusammenhang eine ambivalente Rolle: Einerseits postulierte sie eine Grundkraft, die nicht per se materiell war, andererseits erwies sich diese aber auch an die Körperlichkeit gebunden. Daß Dauthendey die Schriften Schopenhauers lebhaft rezipierte, belegen mehrere zwischen dem 27. Mai und dem 10. Juli 1891 abgefaßte Briefe an den Freund Siegfried Löwenthal; vgl. Max Dauthendey: Briefe an seine Jugendfreunde 1890-1892, insbesondere an Siegfried Löwenthal, hrsg. und mit einem Vorwort versehen von Daniel Osthoff. Würzburg: Daniel Osthoff Verlag 1993, S. 49ff. Aus dieser Zeit datiert im übrigen eine auf Schopenhauer bezügliche Notiz im Nachlaß; vgl. H.[erman] G.[eorg] Wendt: Max Dauthendey poet-philosopher, S. 27. Nach Wendts Recherchen habe Dauthendey mas early as 1890 [...] enthusiastically" Schopenhauer gelesen; ebd., S. 26. Mehr noch: Seine "preoccupation with Schopenhauer habe mindestens bis zu seinem Schwedenaufenthalt im Jahre 1893 angedauert, während dessen die zweite Hälfte der in Uitra Violett versammelten Texte entstand; ebd., S. 27. Zugleich sei 
tungsparadigma, das nicht nur die naturphilosophische Überwindung einer rein materialistischen Weltsicht, sondern damit einhergehend auch eine ästhetische Rehabilitation des ,Poetischenc versprach. ${ }^{11}$ Der eingetretene Bedeutungsverlust dichterischen Ausdrucks in der Moderne schien nämlich dann kompensierbar, wenn die Literatur sich nicht länger als exklusives und novitätsfeindliches Reservat des Geistes verstand, sondern sich selbst zum sinnlichen Ausdrucksmedium aktueller naturwissenschaftlicher Theoriebildung machte. ${ }^{12}$

Ausgehend von einer derartig monistischen Weltsicht, die bei ihm zu einem eklektischen Panpsychismus weiterentwickelt ist, formulierte Dauthendey dann seine neuen ästhetischen Prinzipien. In ausführlicher Form entfaltet sind sie in der vantinaturalistischen Programmschrifte" ${ }^{13}$ Newe Ideale, die 1893 - übersetzt von Carl Gustav Uddgren - unter dem Titel Verdensaltet. Det nye sublime $i$ kunsten auf schwedisch erschien. ${ }^{14}$ Dauthendey stellt darin die Leitmaxime auf, der Künstler solle sich bei seiner Arbeit rein auf das wahmehmende Subjekt konzentrieren und so genau wie möglich die "Eindrücke von Außen und der damit verbundenen Assoc[i]ationen in einem einzelnen Ich ${ }^{15}$ zu registrieren versuchen. Das protokollarische Ethos, das hinter dieser Forderung steht, verbindet seinen Ansatz zwar noch mit der Ästhetik des Naturalismus, doch geht es dabei gerade nicht mehr um eine mimetische "Abschrift der Natur " ${ }^{16}$, wie sie sich mittlerweile auch mit Hilfe von photo- und phonographischen Reproduktionsapparaturen ${ }^{17}$ herstellen ließ, sondern vielmehr um ihre sensualistische Neuerschaffung. Nicht zuletzt also dic aufkommende Medienkonkurrenz

Dauthendey nicht nur "familiar with Nietzsche's works" gewesen, in seinen Texten würden sich auch mumerous references« auf dessen Ideologeme finden; ebd., S. 28 (dort auch einzelne Belege).

1 Vgl. hierzu auch Kurt Bayertz: Die Deszendenz des Schönen. Darwinisierende Ästhetik im Ausgang des 19. Jahrhunderts.

12 Siehe hierzu Antoon Berentsen: "Vom Umebel zum Zukunftsstaat火. Zum Problem der Popularisierung der Naturwissenschaften in der deutschen Literatur (1880-1910). Berlin: Verlag Peter Oberhofer 1986 (= Studien zu deutscher Vergangenheit und Gegenwart 2).

Elke Austermühl: Lyrik der Jahrhundertwende. In: Hansers Sozialgeschichte der deutschen Literatur vom 16. Jahrhundert bis zur Gegenwart. Bd. 7: Naturalismus/Fin de siècle/Expressionismus 1890-1918. Hrsg. von York-Gothart Mix. München/Wien: Hanser 2000, S. 356.

14 Wendt bemerkt über diesen Text Dauthendeys: Verdensaltet. Det nye sublime $i$ kunsten "furnishes the key to his early literary endeavors«; H. [erman] G.[eorg] Wende Max Dauthendey poet-philosopher, S. 13. Die bis heute unpublizierte deutsche Version des Textes befindet sich im Dauthendey-Nachlaß des Stadtarchivs Würzburg. Stadtarchiv Würzburg, Nachlaß 28: Max Dauthendey, Signatur P 41/2. Ebd., Signatur P 41/3.

17 Insbesondere erstere kannte Dauthendey aus eigenem Umgang, hatte er doch Anfang der neunziger Jahre im photographischen Atelier seines Vaters in Würzburg mitgearbeitet. Zum Stellenwert des neuen Mediums vgl. Gerhard Plumpe: Der tote Blick. Zum Diskurs der Photographie in der Zeit des Realismus. 
zwischen Literatur und technischen Aufzeichnungssystemen nötigte die Autoren der frühen neunziger Jahre dazu, das geltende naturalistische Paradigma zu modifizieren oder ganz zu verlassen.

Ähnlich wie viele seiner Kollegen wandte sich auch Dauthendey von der Schilderung der wétats de choses « ()Sachenständer" ${ }^{18}$ ) ab und propagierte statt dessen eine "Kunst des Intimen “" d'âmes« ("Seelenstände " ${ }^{20}$ ) sei. Anders aber als etwa die Vertreter der Wiener Moderne war er nicht an der Erforschung der menschlichen Psyche interessiert, sondern richtete sein Augenmerk ausschließlich auf den Vorgang der Perzeption. Weniger das Innere des Individuums sollte ergründet werden als vielmehr die rezeptive Spiegelung des sAußen durch das wahrnehmende Ich. Unter Rückgriff auf den Empiriokritizismus Ernst Machs ${ }^{21}$ versteht Dauthendey die Realität als chaotische Vielfalt von empirischen Daten, die, bei der Perzeption durch ein Subjekt, in diesem die unterschiedlichsten Sensationen auslösen. ${ }^{22}$ Diese "Stimmungen« (D-GW I, S. 548) in Sprache zu transformieren und sie - unter Rückbezug auf die sie bewirkenden Reizmomente - literarisch zu erfassen, wird fortan für ihn zur vornehmsten Aufgabe des Schriftstellers. So müßten etwa unter wAusnützung aller Sinne: der Töne Farben - des Geruches - der Empfindung u. des Geschmackes« die »Reize aller Wahrnehmung auf eine jeweilige Grundstimmung “ ${ }^{23}$ wiedergegeben werden.

In gut pantheistischer Tradition erscheinen dabei die reizauslösenden Momente der kosmisch verstandenen Natur als Ausdnuck des Erhabenen. Und da die mewigen Farben u. eurgen Töneu als mmächtige Laute des Erhabenen« gedeutet werden, gelangt Dauthendey zu der Schlußfolgerung: "Die Künstler des Erhabenen müssen das

18 Hermann Bahr: Die neue Psychologie [1890]. In: H. B.: Die Überwindung des Naturalismus. Theoretische Schriften 1887-1904, S. 55.

19 Stadtarchiv Würzburg, Nachlaß 28: Max Dauthendey, Signatur $P$ 41/2. Zumindest in der Wortwahl schließt er sich damit dezidiert an Maurice Maeterlinck an, der etwa zur selben Zeit das intime Theater begründete. Der enge Bezug zu dem belgischen Autor zeigt sich auch daran, daß Dauthendey Anfang der neunziger Jahre dessen Dramen L'Intruse und Les Aveugles ins Deutsche übersetzte. Hess meint sogar, erst »die Entdeckung Maeterlincks» habe "die Formulierung eines poetischen Konzepts« erlaubt, "das in Uttra V'iolett kulminiert"; Günter Hess: Dauthendeys Sommer oder Wie man in Würzburg zum Dichter wird. In: Max Dauthendey 1867-1992. Reden zu seinem 125. Geburtstag. Hrsg. von Gabriel Engert und Daniel Osthoff. Würzburg. Daniel Osthoff Verlag 1992, S. 17. Hermann Bahr: Die neue Psychologie [1890], S. 55.

21 Vor allem dessen Beiträge zur Anafyse der Empfindungen (1886) haben bekanntlich nachhaltig auf die ästhetischen Konzepte der Jahrhundertwende eingewirkt; vgl. hierzu das entsprechende Kapitel bei Manfred Diersch: Empiriokritizismus und Impressionismus. Über Beziehungen zwischen Philosophie, Ästhetik und Literatur um 1900 in Wien. Berlin (Ost): Rütten \& Loening 1973 (= Neue Beiträge zur Literaturwissenschaft 36), S. 13-45. Der mechanische Charakter dieses Reiz/Reaktions-Schemas gemahnt noch deutlich an den Determinismus des Naturalismus.

23 Stadtarchiv Würzburg, Nachlaß 28: Max Dauthendey, Signatur P 41/2. 
Empfindungsleben der Farben, Töne, in allen leisen Erregungsgraden beobachten lernen." ${ }^{24}$ Mit einem Mal schlägt so der ursprünglich ästhetische Impetus des Registrierens um in das Bestreben, das Dargestellte zu verherrlichen. Literatur wird geradezu zum Medium der künstlerischen Anschauung von Transzendenz, wobei diese Transzendenz natürlich eine säkulare ist. In einem Brief an die Freunde Arnold Villinger und Siegfried Löwenthal umreißt Dauthendey seine Zielvorstellungen folgendermaßen:

Mein jetziges Streben ist, das wieder in die Kunst aufzunehmen, was wir früher das Große, das Erhabene nannten. [...] Es gibt ein Gefühl Erhabenheitc. Und dieses muß wieder in die Dichtung kommen, oder besser: aus ihr strömen.

[...] Da wir sogenannten gebildeten Menschen keine Götter wie die Griechen haben und keine überschwänglichen politischen Gefühle, so bleibt das Erhabene nur noch allein in der gewaltigsten Naturdichtung. ${ }^{25}$

Dementsprechend spielen Naturerscheinungen in Dauthendeys erstem ,GedichtBand Ultra Violett (1893) eine tragende Rolle, wie bereits ein Blick auf die Titel der Texte verdeutlicht: Blütenleben, Die Welle, Im Bucbenwald, Faulbaumduft, Kuckuckruf, Amselsang, Rosenduft, Wolkenschatten, Resedaduft, Regenduft, Meerwassergeruch, Reif, Erster Schnee, Werdender Mond/Vollmond/Schwindender Mond/Toter Mond, Stemschnuppe. Nicht selten werden dabei die einzelnen Phänomene in ihrem Bezug zu unterschiedlichen Tages- (Morgenduft, Abend) oder Jahreszeiten (Frübling, Johanni, Herbstbacchanal, Herbstflammen, November, Wintersonne) gezeigt. Menschen kommen in diesen Texten dagegen kaum vor - und wenn, dann geben sie wenig mehr als eine bloße Staffage für das dominierende Natursgeschehen ab.

Das von Dauthendey skizzierte ästhetische Programm erfordert vom Künstler freilich nicht nur besondere Sensibilität bei der Wahmehmung, sondern auch eine neuartige Handhabung der literarischen Mittel. Gemäß der Maxime, die sich in einem Notizbuch aus dieser Zeit findet: „Versmaß muß mit der Stimmung wie Musik wanken. Und schneller, knapper und gedehnter werden. Gleichgültig und knorrig gereimt je nach der Wucht des Inhalts « ${ }^{26}$, versucht der Autor deshalb die sprachlichformale Gestaltung seiner Texte den unterschiedlichen Naturerscheinungen anzupassen. So weist er etwa in dem aus vierhebigen Trochäen bestehenden, gereimten Versgedicht Johanni - verfahrenstechnisch durchaus konventionell - einer zweihebigen Waisenzeile die Aufgabe zu, die starke Verkürzung der Nacht zur Sommerson-

24 Ebd., Signatur P 41/3. In Umsetzung dieser Fordenung schreibt er am 17. April 1893 an seine Freunde Amold Villinger und Siegfried Löwenthal: „Nur mit starken Eindrücken, wie sie unsere Sinne erhalten, suche ich das Empfinden wiederzugebenc, Max Dauthendey: Ein Herz im Lärm der Welt. Briefe an Freunde. München: Albert Langen/Georg Müller 1933, S. 116. Ebd.

26 Zitiert nach: H.[erman] G.[eorg] Wendt: Max Dauthendey poet-philosopher, S. 66, Anm. 25. 
nenwende formal wirkungsvoll wiederzugeben. Eine derartige Funktionalisierung von Metrum und Reim gehört freilich zu den Ausnahmen der in Ultra Violett versammelten Texte. In den meisten verzichtet Dauthendey gerade auf herkömmliche lyrische Gestaltungsmittel und versucht, "Styl u. Reim der früheren Poesie ${ }^{27}$ durch flexible Ausdrucksweisen wie freie Rhythmen oder gänzlich ungebundene Rede zu ersetzen. ${ }^{28}$ Wie ein Blick auf die im Nachlaß erhaltenen Entwürfe zeigt, betrachtete er dabei ,Vers - und Prosaform als konvertible Gestaltungsmöglichkeiten: "Auch die Prosa schrieb Dauthendey zunächst freirhythmisch in unregelmäßigen Versgruppen. Der Text dieser Erstfassungen ist völlig identisch mit der späteren Form; lediglich die Versordnung ist aufgehoben. ${ }^{29}$

Die formale Entgrenzung geht aber zugleich einher mit der Tendenz zur Ökonomisierung und Pathetisierung des Stils. ${ }^{30}$ So schreibt Dauthendey am 17. April 1893 an seine Freunde Arnold Villinger und Siegfried Löwenthal: »Ich suche jetzt in meiner Dichtung immer gedrängter zu werden. Das kleinste überflüssige Wort soll wegfallen. ${ }^{31}$ Die angestrebte verbale Komprimierung erreicht er zum einen, indem er weitgehend auf parataktische Konstruktionen und wvielfach sogar auf eine geschlossene Satzbildung ${ }^{32}{ }^{32}$ verzichtet. In der Überzeugung, daß mjähe knappe Sätze ${ }^{33}$ den flüchtig-momenthaften Charakter der auf das wahrnehmende Ich einströmenden sinnlichen Eindrücke am ehesten sprachlich nachzubilden vermögen, ${ }^{34}$ bevorzugt er mattributiv aufgeladene Substantivreihungen ${ }^{35}$ und eine bewußt elliptische Syntax. ${ }^{36}$ Daneben setzt Dauthendey in bislang ungekanntem Ausmaß Metaphern ein, die gleichfalls im Dienst sprachlicher Ökonomisierung stehen. Begreift man die rhetorische Figur der Metapher im Anschluß an die antike Dichtungslehre (Quinti-

27 Stadtarchiv Würzburg, Nachlaß 28: Max Dauthendey, Signatur P 41/2.

"Rather than delimit the provinces of the arts, he deliberately erased their boundaries", bemerkt Wendt in diesem Zusammenhang zutreffend; H.[erman] G.[eorg] Wendt: Max Dauthendey poet-philosopher, S. 59.

Elisabeth Veit: Fiktion und Realität in der Lyrik. Literarische Weltmodelle zwischen 1890 und 1918 in der Dichtung Max Dauthendeys, Richard Dehmels und Alfred Momberts. Diss. München 1987, S. 28.

Nicht zufälig beklagt er sich denn auch darüber, daß der Idealismus so "pathoskahlu gewesen sei; Max Dauthendey: Ein Herz im Lärm der Welt, S. 117. Ebd., S. 119.

(1) Lyrik der Jahrhundertwende, S. 357

Stadtarchiv Würzburg, Nachlaß 28: Max Dauthendey, Signatur P 41/2.

"Um die Stimmung intim wiederzugeben, muß sich der Styl [...] der fliehenden Erregung anpaßen.w heißt es in Neue Ideak; ebd.

Während sowohl der elliptische Stil als auch die fast ausschließliche Bevorzugung des Präsens als Zeitform nach den Vorstellungen des Autors eigentlich dazu dienen sollen, das dargestellte Geschehen dem Leser schockartig zu vergegenwärtigen, bewirken sie im Endeffekt eher das Gegenteil: Dynamik erscheint stillgestellt in einzelnen unbewegten Zustandsbildern. 
lian) als mum die Partikel swier verkürzten Vergleich ${ }^{37}$ oder im Sinne moderner linguistischer Theoriebildung als wverdichtete Analogie ${ }^{38}$ bzw. »kondensierten Vergleich ${ }^{39}$, dann wird deutlich, daß diese tropische Form der Rede in jedem Fall zu einer deutlichen Verknappung der Wortmenge führt. Zugleich dient sie der »semantischen Verdichtung ${ }^{40}$ (»condensation sémantiquer). Auf diese Weise können die vielfältigen "Sinnesreizungen - wie vom Autor gefordert - mit weinem einzigen schnellumfassenden Wort« wiedergegeben werden, sin dem sich die ganze Empfindung konzentriert ${ }^{41}$.

Die bewußte Arrangierung von sstarken, greifbaren Bildern ${ }^{42}$ zu Metaphernclustern läßt natürlich im Ergebnis Sprachgebilde entstehen, die zum Hermetischen tendieren. $^{43}$ Doch auch wenn ineinander verschlungene "Bilderketten« (D-GW I, S. 548) das Verständnis der Texte erheblich erschweren, kündigt Dauthendey die Verbindung zwischen Sprachzeichen und außersprachlichem Wirklichkeitskorrelat nie wirklich auf. Zwar lockert er den Konnex zwischen beiden an vielen Stellen soweit, daß die einzelnen Lexeme ein regelrechtes Eigenleben gewinnen, gleichwohl bleibt ihre Verweisfunktion auf eine unabhängig von ihnen existierende Realität durchweg erhalten. ${ }^{44}$ Es würde deshalb am Charakter dieser Texte vorbeigehen, wenn man sie als Beispiele für jene vollständige Autonomisierung der Dichtungssprache anführen wollte, um deren Aufweis in der deutschen Literatur sich besonders die Tübinger Forschergruppe um Gotthart Wunberg bemüht hat. ${ }^{45}$ Von einer

37 Gerhard Kurz: Metapher, Allegorie, Symbol. 3., bibliographisch ergänzte Auflage. Göttingen: Vandenhoeck \& Ruprecht 1993 (= Kleine Vandenhoeck-Reihe 1486), S. 8.

Chaïm Perelman/Lucie Olbrechts-Tyteca: Traité de l'argumentation. La nouvelle rhétorique. Bruxelles: Éditions de l'Université de Bruxelles ${ }^{3} 1976$ (= Collection de sociologie générale et de philosophie sociale), S. 535. Stephen Ullmann: Semantik. Eine Einfühnung in die Bedeutungslehre [1964]. Frankfurt a.M.: S. Fischer 1973 (= Conditio humana), S. 266.

40 Jacques Lacan: Funktion und Feld des Sprechens und der Sprache in der Psychoanalyse. In: J. L.: Schriften. Ausgewählt und hrsg. von Norbert Haas. Übersetzt von Rodolphe Gasché, N. H., Klaus Lehmann und Peter Stehlin unter Mitwirkung von Chantal Creusot. Weinheim/Berlin: Quadriga 1986, S. 107. Stadtarchiv Würzburg, Nachlaß 28: Max Dauthendey, Signatur P 41/2. Max Dauthendey: Ein Herz im Lärm der Welt, S. 117. Im Brief an Siegfried Löwenthal vom 17. Juli 1893 schwärmt Dauthendey von der "Bildersprache der Düfte, Farben und Töne der Naturi; ebd., S. 119.

43 Ein typisches Beispiel für diese Tendenz stellt etwa das Versgedicht Jasmin dar.

44 Ein unmißverständlicher Beleg dafür ist auch die Tatsache, daß Dauthendey in seinen tagebuchartigen Notizheften sich derselben sprachlichen Verfahren bedient. Zuweilen finden sich darin auch bereits Vorstufen später veröffentlichter Texte, vgl. etwa Max Dauthendey: Frühe Prosa. Aus dem handschriftlichen Nachlaß hrsg. von Hermann Gerstner unter Mitarbeit von Edmund L. Klaffki. München/Wien: Langen/Müller 1967, S. 99 und 169-171.

$45 \mathrm{Vgl}$. in diesem Zusammenhang Gotthart Wunberg. Unverständlichkeit. Historismus und literarische Modeme. In: Hofmannsthal-Jahrbuch zur europäischen Modeme 1 (1993), S. 309-350; Moritz Baßler: Die Entdeckung der Textur. Unverständlichkeit in der Kurz- 
tatsächlichen wKontingenz der Dauthendeyschen Lexemfolgen ${ }^{46}$, die eine hermeneutische Lektüre unmöglich mache, kann denn auch weder im Hinblick auf das Frühwerk noch auf die Sprachverwendung in den späteren Texten die Rede sein. In beiden Fällen zielt der sprachschöpferische Impetus des Autors vielmehr bewußt auf die Erfassung eines vitalistisch gedachten Weltsubstrats. ${ }^{47}$

Bei der Realität, auf die dabei Bezug genommen wird, handelt es sich freilich nicht mehr um die vertraute Erfahrungsumwelt, wie sie noch der Texttypus des Erlebnisgedichts voraussetzt, sondern um eine Wirklichkeit, die den oben umrißhaft skizzierten zeitgenössischen (populär-)philosophischen Natur- und Wahrnehmungstheorien entspricht. Nicht zufälig trägt Dauthendeys Band den Titel Ultra Violett, gibt doch dieses erst wenige Jahre vor dessen Erscheinen entdeckte Naturphänomen die ideale Metapher ab für die Gesamtheit all jener Wirklichkeitsaspekte, die - obgleich existent - dem Menschen gemeinhin verborgen bleiben, weil er sie mit seinen Sinnen nicht ohne weiteres erkennen kann. Die ultraviolette Strahlung markiert mithin, gerade weil sie - wie es im Proömion der Textsammlung heißt - sunsichtbar" (D-GW IV, S. 9) ist, genau jene Dimension, die es, wissenschaftlich wie poetisch, erst noch zu entdecken gilt. Der paradoxe Charakter des Ultraviolett, der darin besteht, daß es zwar eine Form von sLichtr darstellt, dennoch aber nicht vom menschlichen Auge wahrgenommen werden kann, liefert zudem ein schlagendes Argument für die Überlegenheit des Darstellungsmaterials Sprache gegenüber den konkurrie-

prosa der emphatischen Moderne 1910-1916. Tübingen: Niemeyer 1994 (= Studien zur deutschen Literatur 134), sowie Moritz Baßler/Christoph Brecht/Dirk Niefanger/Gotthart Wunberg: Historismus und literarische Modeme. Mit einem Beitrag von Friedrich Dethlefs. Tübingen: Niemeyer 1996.

46 Moritz Baßler: Oberflächen. Die geflügelte Erde von Max Dauthendey. In: Munich 1900 site de la modemité / München 1900 als Ort der Modeme. Ed. par/Hrsg. von Gilbert Merlio et/und Nicole Pelletier. Bern/Berlin/Frankfurt a.M./New York/Paris/Wien: Lang 1998 (= Jahrbuch für Internationale Germanistik A/47), S. 210.

47 Dies unterscheidet Dauthendey auch von Vertretern der literarischen Phantastik, denen es um die Generierung autonomer Textwelten geht. Daß ein Autor wie Paul Scheerbart die ästhetischen Zielsetzungen des jungen Würzburger Schriftstellers als seinen eigenen verwandt empfand - er zeigte sich von dessen visionären Texten so wenthusiasmiert", daß er Ulitra Violett win Fortsetzungen in seinem Phantastischen Sammelbuch erscheinen lassen火 wollte -, muß deshalb wohl als Projektionsphänomen gedeutet werden; Max Dauthendey: Briefe an seine Jugendfreunde $1890-1892$, S. 221. Dauthendey selbst war von dem ihm entgegengebrachten Interesse und mehr noch von den sich daraus ergebenden Publikationsaussichten zwar sichtlich geschmeichelt, signalisierte aber von Anfang an, daß er seine Texte nicht als sphantastischer Literatur verstanden wissen wollte. So bemerkt er in seiner Autobiographie über Scheerbarts Vorhaben, einen regelrechten »Verlag der Phantasten« zu gründen: "[...] der Titel ,Phantasten gefiel mir gar nicht. Er nahm der Phantasie die Würde und kam mir für den Dichter entwürdigend vor." (D-GW I, S. 549) Diese Abgrenzung verdeutlicht noch einmal, daß es Dauthendey eben nicht um den sprachlichen Aufbau einer autonomen Gegenwelt zur Realität, sondem um die Erschließung neuer Wirklichkeitsbereiche mit den Mitteln der $>$ Dichtung ging. 
renden technischen Aufzeichnungsapparaturen. Was die auf Abbildung der Oberfläche der Dinge beschränkte Photographie nicht erfassen kann, ist dem Medium der Literatur sehr wohl zugänglich. Der Mensch muß sich demnach für Wirklichkeitsbereiche öffnen, die er bisher ignoriert hat. Sobald das wahrnehmende Subjekt dies tut, werden sich ihm - so die kühne Verheißung des spoet-philosopher" ${ }^{48}$ Max Dauthendey - meue Welten“ (D-GW IV, S. 9) erschließen.

Von hier aus läßt sich nun auch der Status von Dauthendeys Texten genauer bestimmen. Da es für ihn keine tote Materie gibt, vielmehr das Universum in seiner Gesamtheit wie in seinen Einzelteilen als belebt und damit grundsätzlich auch als menschenähnlich gedacht wird - "Jedes Atom ist ein empfindendes Ich ${ }^{49}$ heißt es in einem Brief an Siegfried Löwenthal vom 17. Juni 1893 -, ist es Aufgabe der Dichtung, die panpsychistisch-anthropomorphe Gestalt des Seins selbst zum Ausdruck zu bringen. Dauthendeys ästhetisches Programm zielt also darauf ab, wdas Reden der Dinge an sich (D-GW I, S. 310) zu belauschen und es in Schriftzeichen zu überführen - gemäß der Prämisse: »Das neue Ideal der Kunst des Erhabenen ist jetzt das Empfindungsleben des Weltalls. ${ }^{50}$ Dabei unterschlägt er freilich, daß das Postulat von der 'Sprache der Dinger eben nur eine Metapher ist. Selbst wenn man den Dingen Ausdrucksvermögen und -qualität zugestehen will, bleibt letztere doch nonverbal. Zwischen res und verba muß also notgedrungen ein Transpositionsakt vorgenommen werden. Naturerscheinungen rufen bestimmte Eindrücke und Stimmungen beim wahrnehmenden Subjekt hervor, das nun damit beschäftigt ist, seine Empfindungen in menschliche Sprache zu übersetzen. Was auf den ersten Blick wie ein impressionistischer Vorgang wirkt, erweist sich bei näherer Betrachtung als expressiv-sprachschöpferische Verfahrensweise. Austermühl hat denn auch mit Recht darauf hingewiesen, daß bei Dauthendey nicht eigentlich mehr beschrieben, sondern Realität nur noch "sprachlich wirkungsvoll simuliert" ${ }^{51}$ werde. Zwar gibt es bei ihm durchaus noch Wahrnehmungsstimuli, die diesen behauptetermaßen zugrundeliegenden Realitätskorrelate jedoch verflüchtigen sich zunehmend. Da sich im Zuge der vitalistischen Dynamisierung der Wirklichkeit das Universum in seine Einzelbestandteile auflöst, verlieren auch die herkömmlichen Begriffe ihren Bezug. So kommt es, daß die Titel von Dauthendeys Gedichten fast durchweg Konkreta benennen, diese in den Texten selbst aber oft nicht mehr erkennbar sind. Ein Rückschluß von der Beschreibung auf das Beschriebene erweist sich in vielen Fällen als unmöglich. Dies freilich bedeutet nichts anderes, als daß die sprachlichen Mittel, die

48 Als einen solchen versucht Wendt den Autor in seiner Dauthendey-Monographie darzustellen; vgl. H. [erman] G. [eorg] Wendt: Max Dauthendey poet-philosopher.

49 Max Dauthendey: Briefe an seine Jugendfreunde 1890-1892, S. 220.

50

51 Stadtarchiv Würzburg, Nachlaß 28: Max Dauthendey, Signatur P 41/3.

Elke Austermühl: Lyrik der Jahrhundertwende, S. 356. 
angeblich im Dienst der Erfassung und Wiedergabe momentaner Aspekte des $\mathrm{Na}$ turgeschehens stehen, sich zumindest partiell zu verselbständigen drohen.

Um die völlige Loslösung des Wortmaterials zu verhindern, die seinem ästhetischen Programm zuwiderlaufen würde, bemüht sich Dauthendey sichtlich darum, seine Texte in allegorische Verweisungszusammenhänge einzubinden. So dient etwa die Wahl der kalendarischen Sommersonnenwende in Johanni dazu, die an sich banale Abfolge zweier Jahreszeiten derart zu inszenieren, daß die zunächst machtvolle Entfaltung der Vegetation in Kombination mit ihrem anschließenden, ebenso unaufhaltsamen Niedergang zur allegorischen Feier einer vitalistisch verstandenen AllNatur wird. In scharfem Gegensatz zu barocken Vanitas-Darstellungen ${ }^{52}$ erscheint Vergänglichkeit aber nun nicht mehr als beklagenswertes Los alles Irdischen, sondern wird geradezu zum triumphalen Beleg der säkularisierten kosmischen Schöpfungsdynamik, innerhalb derer Zerstörung lediglich die notwendige Voraussetzung für eine Erschaffung neuen Lebens ist. Die Tatsache, daß besonders die Prosagedichte des Bandes Ultra Violett Allegorisierungen aufweisen, hängt wohl vor allem damit zusammen, daß der - gegenüber den Versgedichten - größere Umfang der Prosatexte den Aufbau entsprechender Bedeutungskomplexe erleichtert. Doch auch die Kenntnis einschlägiger Referenztexte aus der Gattungstradition dürfte dazu beigetragen haben, daß Dauthendey wesentliche Teile seiner Kurzprosa an allegorischen Mustern ausgerichtet hat. ${ }^{53}$

Sucht man nach Vorbildern für die eigenwillige Gestaltungsweise, derer sich der Autor in seiner dichterischen Frühphase bediente, dann bieten sich zunächst die Vertreter der Münchner Moderne als naheliegende Bezugsgröße an, mit denen Dauthendey das Bemühen um eine von Gattungskonventionen weitgehend freie Dichtkunst teilte. ${ }^{54}$ Vor allem Otto Julius Bierbaums Prosaparaphrasen von Werken der

52 In dem analog strukturierten Gedicht Herbstbacchanal, das Jobanni unmittelbar folgt, wird sogar der aus dem Kontext barocker Dichtung geläufige "Todtenwumm (D-GW IV, S. 40) als allegorisches Element bemüht.

53 Die aus den Jahren 1891 und 1892 stammenden, zu Lebzeiten unveröffentlichten "Skizzen« Vom Kampfplat, Ein Park, Todusnd und Ein Märchen der Zukunft verweisen relativ deutlich auf die Vorbildwirkung der moralistischen Allegorien Turgenevs bzw. Liliencrons; vgl. Max Dauthendey: Frühe Prosa, S. 150-157 und 176-179.

$\mathrm{Da}$ Dauthendey nachweislich nicht nur Texte von Vertretern der Münchner Moderne gekannt, sondem auch persönliche Kontakte mit ihnen gehabt hat, steht jedenfalls fest. Wie der Autobiographie Gedankengut aus meinen Wandegjabren zu entnehmen ist, hat Dauthendey die sjunge [deutsche] Literaturu zum ersten Mal 1890 und zwar waus der Zeitschrift Dic Gesellschaft kennengelernt» (D-GW I, S. 402). Eine frühe Erwähnung Croissant-Rusts findet sich in einer seiner tagebuchartigen Aufzeichnungen. Dort notiert Dauthendey am 28. Juni 1891 anläßlich eines Dorffestes: „Für einen Realisten à la Conrad oder Croissant-Rust - eine Fundgrube köstlicher Romanmotive“; Max Dauthendey: Frühe Prosa, S. 116. Diese Bemerkung kehrt fast wörtlich auch im Brief an Siegfried Löwenthal vom 29. Juni 1891 wieder; vgl. Max Dauthendey: Briefe an seine Jugendfreunde 1890-1892, S. 100. Bierbaum begegnete der aus Würzburg stammende Autor mim Frühjahr 1892" (D-GW I, S. 415) wäh- 
bildenden Kunst dürften Dauthendey entscheidende Anregungen für seine eigenen Texte vermittelt haben. Immerhin handelt es sich bei der Hälfte der 14 in Ultra Violett enthaltenen Prosatexte um Bildbeschreibungen. ${ }^{55}$ Am Beispiel Bierbaums konnte Dauthendey nicht nur erfahren, wie sich optische Eindrücke mit Worten so wiedergeben lassen, daß die Beschreibung eine eigene ästhetische Qualität gewinnt, er bekam durch ihn auch die grundsätzliche Eignung der Prosa für die Gestaltung spoetischerc Gegenstände vermittelt. Geradezu mit Händen zu greifen ist das Filiationsverhältnis, wenn man einen Blick auf Bicrbaums Sprachverwendung wirft. Denn in mehreren Texten der Erlebten Gedichte begegnet zumindest ansatzweise bereits jene expressive, an der Benennung von Farbvaleurs orientierte Sprache, die sich in ihrer Bildlichkeit zunehmend von der Wiedergabe einer sinnlichen Realität zu emanzipieren scheint, wie man sie aus Ultra Violett kennt. Beim direkten Vergleich treten aber auch die Unterschiede im Vorgehen der zwei Schriftsteller deutlich hervor - und zwar besonders im Hinblick auf Syntax und Klanggestalt der Texte: So dominieren bei Bierbaum, anders als bei Dauthendey, eindeutig Satzgefüge mit vollständiger syntaktischer Struktur. Außerdem sucht der Münchner Autor seiner Kurzprosa durch den ausgiebigen Gebrauch von Rekurrenzen Kohärenz und Poetizität zu verleihen. Demgegenüber verzichtet Dauthendey bei der Gestaltung seiner Texte weitgehend auf klangliche Mittel; dafür greift er in viel stärkerem Maß als Bierbaum auf das Ausdrucksmittel der Metapher zurück. Immerhin nutzen beide bei ihren Prosagedichten übereinstimmend, wenn auch in ganz unterschiedlicher Form, traditionelle Verfahrensweisen der Lyrik.

Bezogen auf die Geschichte der Gattung Prosagedicht in Deutschland nimmt Dauthendey das bereits erprobte Modell der Mischpublikation von Texten in gebun-

rend eines München-Besuchs. Bei diesem Zusammentreffen wurde Dauthendey offensichtlich auch zur Mitwirkung an dem von Bierbaum neugegründeten Modemen Musen-Almanach eingeladen, dessen Jahrgang 1893 einen Vorabdruck aus Ultra Violett bringt. Die Annahme, daß Dauthendeys "Prosaskizzen nach französischen Vorbildem" gestaltet seien, erscheint dagegen reichlich spekulativ; Günter Hess: Dauthendeys Sommer oder Wie man in Würzburg zum Dichter wird, S. 19. Bislang gibt es keinerlei Belege dafür, daß Dauthendey Anfang der neunziger Jahre schon Prosagedichte von Baudelaire, Huysmans, Rimbaud oder Mallarmé kannte.

55 Im heute äußerst selten gewordenen Erstdruck werden sie namentlich genannt: „Paradies (p. 11), by Viggo Petersen; $A$ V'espero (p. 12), by Gerolamo Cairato; Das beilige Fexer (p. 15), by Otto Sinding, Die Welle (p. 17), by Julius Exter; Frïbling (p. 38), by Ludwig von Hofmann; Wintersonne (p. 40), by Hans Olde; and Flucht nach Egpten (p. 42), by xxx.« H.[erman] G. [eorg] Wendt: Max Dauthendey poet-philosopher, S. 62, Anm. 9. Dazu kommt noch der nach Edvard Munchs Der Kopf des Ertrunkenen gestaltete Text Vision; vgl. Edmund Klaffki: Max Dauthendeys lyrische Anfänge. Ulira Violett und frühe Lyrik nach den Handschriften aus dem Nachlaß. Magisterarbeit (Masch.) Frankfurt a.M. 1975, S. 52. Die sprachliche Gestaltung entfemt sich freilich von den bildkünstlerischen Vorlagen in gleichem Maße wie von den geschilderten Naturphänomenen; beide Male geht es nicht um eine mimetische Wiedergabe der Bezugsobjekte. 
dener und ungebundener Sprache auf, erweitert es freilich noch durch zwei "Sangdichtungen«, die zum einen Vers und Prosa in einem einzigen Textgebilde miteinander verbinden, zum anderen durch die Einführung mehrerer Sprecherinstanzen bewußt auch Anleihen bei dramatisch-szenischen Genremustern nehmen. Das Ziel dieser Veröffentlichungspraxis besteht darin, die traditionelle Gattungstrias Epik/ Lyrik/Dramatik zu überwinden, indem die einzelnen Gestaltungsweisen textuell fusioniert werden. Daß eine derartige Integration unterschiedlicher Ausdrucksmodi fast zwangsläufig auch den Umfang der Texte anschwellen läßt, kann man bereits an den erwähnten "Sangdichtungen« ablesen, die nicht nur zu den längsten in Ulita Violett enthaltenen Textgebilden gehören, sondern durch die Placierung ganz am Ende des Bandes auch eine Art Summe des darin Dargebotenen darstellen.

Im weiteren Verlauf der Werkentwicklung wird diese Tendenz von Dauthendey dann konsequent fortgesetzt. ${ }^{56}$ Während er sich in den neunziger Jahren in einer Vielzahl einzelner Gattungen - Roman, Lyrik, Drama - erprobt, wendet er sich spätestens seit der Jahrhundertwende bevorzugt literarischen Großformen ${ }^{57} \mathrm{zu}$, welche die verschiedenen Genres zu integrieren suchen. Die Vereinigung des bislang Getrennten geschieht dabei immer unter dem Vorzeichen des )Poetischen - obgleich sich die so entstehenden Werke im Ergebnis als zuweilen seltsam anmutende $\mathrm{Hy}$ bridgebilde präsentieren. Dauthendey hat mit seinem Euvre denn auch entscheidenden Anteil an der seit Beginn der neunziger Jahre einsetzenden Reauratisierung der Versdichtung. Freilich sind die ausladenden Poeme Die gefigelte Erde (1910) und

56 Zwar stufte Dauthendey die in Ultra Violett enthaltenen Texte im Rückblick als literarische „Entwicklungsversuche" (D-GW I, S. 548) ein, dennoch aber fand bei ihm - anders etwa als bei Bierbaum - später keine Abkehr von den dichterischen Experimenten seiner Jugendzeit statt. Und dies, obwohl er in den Augen der Öffentlichkeit lange Zeit mit seinem Frühwerk identifiziert worden war. Mit leichter Resignation schreibt er denn auch in seiner Autobiographie: "Zwanzig Jahre hindurch konnte ich in fast jeder Kritik, die über meine Art zu dichten geschrieben wurde, das Wort Ultraviolett wiederfinden. Wie die Brandmarke, die man einem Galeerensträfling ins Fleisch brennt, rief man mir fortgesetzt das Abcbuch meiner Lyrik in Erinnerung." (D-GW I, S. 552) Vielmehr faßte Dauthendey seine literarischen Erstlingstexte als notwendige Voraussetzung für sein weiteres Schaffen auf: „Ohne diese Versuche wäre ich nicht zu meiner späteren Dichtungsweise gelangt, und wenn man mich noch einmal in dieselbe Welt setzen würde und in denselben Zeitgeist, in dem ich aufwuchs, ich würde nicht anders handeln können, als ich es getan habe» (D-GW I, S. 548f.). Diese Einstellung bewog ihn schließlich auch dazu, seine frühen Texte zur Gänze in die Ausgabe seiner Gesammelten Werke aufzunehmen und sie so als integraler Bestandteil seines literarischen CEuvres zu kanonisieren.

57 Zur Unterscheidung zwischen ygroßer Form und skleiner Forme vgl. Juri Tynjanow: Das literarische Faktum [1924]. In: J. T.: Poetik. Ausgewählte Essays. Leipzig/Weimar: Gustav Kiepenheuer Verlag 1982 (= Gustav Kiepenheuer Bücherei 35), S. 9 und 19. Schon 1896 erklärt Servaes - im Rückgriff auf Nietzsche - den „Geist des Monumentalen [...] zum Erzieher für den Geist des Modemen«; Franz Servaes: Moderne Monumentalmalerei. In: Neue deutsche Rundschau 7 (1896), S. 284. 
Das Lied der Welfestlicbkeit (1917) keine Versepen üblicher Machart mehr, sondern höchst eigenwillige Neuschöpfungen, welche die traditionellen Verfahren der Versifikation raffiniert unterlaufen. So umfassen die einzelnen ,Verseinheiten der Texte ein, zwei oder drei Sätze und werden über mehrere Zeilen hinweg ausgedehnt bis sie wie Abschnitte eines Prosatextes wirken. Diesem Eindruck allerdings wird dadurch sogleich wieder entgegengesteuert, daß Dauthendey die Einzelelemente seiner Texte mit Binnenreimen versieht und ihnen damit eine aus der Lyrik bekannte klangliche Struktur aufprägt. Er vermeidet so nicht nur die Zuhilfenahme metrischer Strukturierung, sondern auch den konventionellen Endreim und umgeht damit geschickt die Zwänge der Prosodie. Das Ergebnis läßt sich wohl am ehesten als eine Sprachgestalt bezeichnen, welche die Elemente aus den beiden einander ausschließenden literarischen Aussagemodi ,Vers` und `Prosa miteinander verknüpft, ohne daß man sie einem dieser Bereiche eindeutig zuordnen könnte.

Die enge Verklammerung von sgebundener und sungebundener Sprache aber prägt ja bereits die Sammlung Ultra Violett. Hieran wird erkennbar, daß der frühe wie der späte Dauthendey gleichermaßen auf der Suche nach einer zeitgemäßen Dichtungsform ist, die spezifisch moderne Erfahrungen auszudrücken vermag, ohne auf das überholte Repertoire herkömmlicher Metrik und Strophik zurückzugreifen. Lediglich die Lösungswege fallen unterschiedlich aus: Während Dauthendey zunächst Prosagedicht und freie Rhythmen als willkommene Gestaltungsmedien einer zeitgemäßen Dichtung nutzt, strebt er nach 1900 in dem Bemühen, weine mir eigene Lyrik« (D-GW I, S. 443) zu schaffen, zu totalisierenden eposartigen Großformen literarischen Ausdrucks. Der Grund dafür liegt auf der Hand: Vermochten die Texte von Ultra Violett zwar die herkömmlichen Gattungsgrenzen zu transzendieren, so ließ der beschränkte Raum des kurzen Vers- oder Prosagedichts doch nur eine punktuelle Wiedergabe der Welttotalität zu. Anders im Spätwerk mit seiner Ausweitung des literarischen Gestaltungsanspruchs ins Grenzenlose. Hier sprengen sprachliche Monumentalgebilde alle konventionellen Limitationen, ${ }^{58}$ um in der Textgestalt selbst dem universalen Charakter der vitalistischen All-Natur Rechnung zu tragen.

Bei allen radikalen verfahrenstechnischen Neuerungen, die sein (Euvre kennzeichnen, erweist sich Dauthendey insgesamt gesehen doch als ein Innovator, der seine Gestaltungsweisen immer wieder an die Tradition rückzubinden sucht. Statt die für das bestehende Literatursystem konstitutive Dichotomie von sPoesier und Prosa generell in Frage zu stellen, beharrt er nach wie vor auf einem seltsam emphatischen Dichtungsbegriff, unter dessen Ägide er dann eine Erneuerung der sprachli-

58 Zu diesem Phänomen, das sich analog auch bei Autoren wie Amo Holz, Theodor Däubler, Alfred Mombert oder Ludwig Derleth zeigt, vgl. Helmut Koopmann: Entgrenzung. Zu einem literarischen Phänomen um 1900. In: Fin de siècle. Zu Literatur und Kunst der Jahrhundertwende. Hrsg. von Roger Bauer und J.[osef] Adolf Schmoll gen. Eisenwerth. Frankfurt a.M.: Klostermann 1977 (= Studien zur Philosophie und Literatur des neunzehnten Jahrhunderts 35), S. 73-92. 
chen Mittel betreibt. Obschon Dauthendeys Hyperrealismus Texte generiert, die in einigen Fällen nur noch schwer, punktuell auch gar nicht mehr lebensweltlich referentialisierbar sind, hält er letztlich an einem im Kern mimetischen Dichtungsverständnis fest. Deshalb geht Austermühl auch zu weit, wenn sie von Dauthendeys Texten behauptet: "Sie bestehen aus synästhetisch hergestellten Einzelbildern, die eine phantastisch-visionäre und in sich zusammenhanglose Welt der Töne, Gerüche und Farben erzeugen, in der die sogikı außersprachlicher Wirklichkeitszusammenhänge aufgehoben ist. ${ }^{59}$ Eine solche Diagnose trifft auf die Texte Rimbauds und Mallarmés zu, welche den konventionalisierten Konnex zwischen Zeichen und Bezeichnetem aufkündigen, nicht aber auf die Metapherncluster Dauthendeys, die bei aller Verselbständigung des Sprachmaterials doch nach wie vor einem mimetischen Grundimpuls folgen. Es geht dabei freilich nicht mehr um die Abbildung der vertrauten Erfahrungswelt, hat diese sich seit der zweiten kopernikanischen Wende, die der Empiriokritizismus nach Meinung der vom Monismus geprägten Autoren ausgelöst hat, doch unwidernuflich in ein Universum von belebten Energiepartikeln verwandelt. Die Wiedergabe einer vitalistisch gedeuteten Natur kann deshalb prinzipiell die gleiche Dignität beanspruchen wie eine Beschreibung, die mit einem naiven Dingverständnis operiert, zumal das Realitätskonzept der zwei unterschiedlichen Abbildungsmodi gleichermaßen auf einer epistemologischen Prämisse beruht, die als solche nicht hinterfragt wird: Schließlich gehen beide übereinstimmend davon aus, daß sich die außersprachliche Wirklichkeit mit den Mitteln der Sprache tatsächlich erfassen lasse.

Was also prima vista als gleichsam visionäre Schau erscheint, ist letztlich nur der die zeitgenössischen Wahmehmungstheorien umsetzende, verfremdende Blick auf die altbekannte Realität. Dauthendeys Texte sind daher auch prinzipiell auf Referenzialisierbarkeit hin angelegt. Die in der neuartigen sprachlichen Gestaltung unvertraut erscheinenden Phänomene werden entweder bereits durch den Titel, spätestens aber durch einen Schlüsselverweis im Text selbst durchlässig gemacht auf jene Alltagserfahrung, die der Autor bei seinen Lesern voraussetzen kann. In der ästhetischen Neugestaltung erkennt der Rezipient also die Wirklichkeit in neuem Lichte wieder. Anders als die französischen Autoren der radikalen Modeme verläßt Dauthendey den Bannkreis herkömmlicher Logik nicht wirklich, was dazu führt, daß seine Texte seltsam zwischen Mimesis und Abstraktion oszillieren. Indem er einerseits das sprachliche Material soweit autonomisiert, daß es seinen Mitteilungscharakter einbüßt, dieses andererseits aber auf ein naturphilosophisch gedachtes, reales Geschehen bezogen bleibt, entstehen merkwürdig ortlose Allegorien, die zwar über den Texthorizont hinaus verweisen, ihr Signifikat aber notgedrungen verfehlen müssen. Die vermeintlich freie Textsemiose bleibt also im Dienst vitalistisch geprägter Weltanschauung.

59 Elke Austermühl: Lyrik der Jahrhundertwende, S. 357. 
Für den hier erörterten Zusammenhang aufschlußreich ist, daß ein auf Totalität angelegtes ästhetisches Konzept mehr oder weniger direkt aus einem sich selbst wissenschaftlich verstehenden, spekulativen Realitätskonstrukt erwächst. Die bei Dauthendey durchgängig zu beobachtende Tendenz zur Fusionierung von Ausdrucksweisen - sei es die textuelle Verschmelzung von >Poesier und Prosa oder die publikatorische Verklammerung der drei wNaturformen der Dichtung - soll im Bereich der Literatur das verwirklichen, was der Monismus bezogen auf die neuere Entwicklung der Wissenschaften geleistet hat, nämlich eine vollständige Versöhnung der Gegensätze im Zeichen einer präsupponierten Ganzheit. Vers und Prosa sind unter diesem Blickwinkel nur noch geschichtliche Relikte im Rahmen kultureller Evolution, die vor dem Hintergrund neuester naturphilosophischer Erkenntnisse nichtig erscheinen. Der Gattung Prosagedicht kommt vor allem deshalb ein wichtiger Stellenwert ihm Rahmen einer zeitgemäßen Ästhetik zu, weil sie als erste moderne Integrationsform der vormals getrennt existierenden Ausdrucksmodi gelten kann. Bezogen auf die weitere Entwicklung der Literatur bleibt das Genre freilich ein - wenn auch unverzichtbares - Durchgangsstadium auf dem Weg zu jenen totalisierenden Gestaltungsmustern, welche eine noch weiter ausgreifende, entdifferenzierende Aufhebung der partikularen Dichtungsarten ermöglichen.

\section{b. Pathetisierte Prosa als mneue Urpoesie«: Johannes Schlaf}

Ganz ähnliche künstlerische Zielsetzungen wie Dauthendey verfolgte auch der aus Querfurt bei Magdeburg stammende Johannes Schlaf (1862-1941). Bereits während der vergleichsweise kurzen Phase der Zusammenarbeit mit Arno Holz in den Jahren 1888 bis 1892 , die ihm das Etikett eines skonsequenten Naturalisten ${ }^{60}$ eintrug, hatte er damit begonnen, von einem deterministischen Wirklichkeitsverständnis ${ }^{61}$ abzurücken und statt dessen ein Weltbild mauf biologistisch-evolutionistischer Grundla-

60 Die Bezeichnung geht bekanntlich auf Gerhart Hauptmann zurück, der sein Stück Vor Sonnenaufgang (1889) Bjarne P. [eter] Holmsen, dem - angeblichen - Verfasser der im Januar 1889 erschienenen Textsammlung Papa Hamlet, gewidmet hatte, der ihm als wconsequentester Realistı erschien; hinter dem norwegischen Pseudonym verbarg sich freilich niemand anderes als das Autorengespann Johannes Schlaf und Amo Holz.

61 Schlaf berichtet später, wie unvorbereitet ihn während seiner Magdeburger Studienzeit (1884/85) »der erste Anhauch des neuzeitlichen Materialismus, der mit immer rapiderem, gewaltigerem Tempo aufstrebenden Technik, der mechanistischen, spositiven, rexakten Naturwissenschaft" getroffen habe; Johannes Schlaf. Aus meinem Leben. Erinnerungen. Halle: Verlag der Hallischen Nachrichten o.J. [1941] (= HN-Bücherei 29), S. 16. In seinem ersten nach- und gegennaturalistischen Text charakterisiert Schlaf sich denn auch als ehemaligen »kaltblütigen Positivisten«; Johannes Schlaf: In Dingsda [1892]. Leipzig. Insel ${ }^{3 / 4}$ o.]. [1912] (= Insel-Bücherei 20), S. 79. 
ger $^{62} \mathrm{zu}$ entwerfen. ${ }^{63}$ Vollends nach Auflösung dieser Produktionsgemeinschaft wandte er sich konsequent einem naturreligiösen Monismus zu, an dem er auch seine ästhetischen Leitvorstellungen ausrichtete. Den populärwissenschaftlichen $\mathrm{Be}$ zugsrahmen dafür fand er vor allem bei Ernst Haeckel, ${ }^{64}$ dessen universalistisch ausgerichtete Entwicklungslehre von Schlaf allerdings unter Bezug auf Julius Langbehns rückwärtsgewandtes Programm sozialer Entdifferenzierung deutlich kulturkritisch akzentuiert wurde. ${ }^{65}$

Mit der Umstellung seiner Poetik ging ein genereller Fokuswechsel von raußen nach innen und eine Neubestimmung der Funktion von Literatur einher. Nicht mehr Reproduktion war das vorrangige Ziel künstlerischer Gestaltung, sondern Evokation: An die Stelle sezierender ${ }^{66}$ Wirklichkeitsbeschreibung im Dienste naturalistischer Milieutheorie trat mit einem Mal die Darstellung subjektiv-ekstatischer Gefühlszustände, die als empathischer Widerhall eines monistisch gedeuteten, harmonischen Seinskosmos begriffen wurden. Obwohl sich Schlafs Gattungspräferenzen im Gefolge dieses gewandelten Literaturverständnisses nicht signifikant änderten, so erfuhren sie doch eine gewisse Neuakzentuierung. Bis dahin war der Autor vorwie-

62 Dieter Kafitz: Johannes Schlaf - Weltanschauliche Totalität und Wirklichkeitsblindheit. Ein Beitrag zur Neubestimmung des Naturalismus-Begriffs und zur Herleitung totalitärer Denkformen. Tübingen: Niemeyer 1992 (= Studien zur deutschen Literatur 120), S. 83.

63 Beleg dafür ist der bereits 1890 veröffentlichte Prosatext Abseits, der später das erste Kapitel von Schlafs Buch In Dingsda (1892) bildete; vgl. Johannes Schlaf: Abseits. In: Freie Bühne für den Entwickelungskampf der Zeit 1 (1890), S. 579-584. Nach eigener Aussage des Autors sind auch die übrigen Texte des Bandes bereits nim Sommer 1890 entstanden“; Johannes Schlaf: Walt Whitman. Zur Einführung. Mein Verhältnis zu Walt Whitman. In: Die Lese 3 (1912), S. 437.

Nach Schlafs eigener Aussage hat er sich wschon als Primaner [...] an der Hand von Häckels Anthropogenie und Natïrlicher Schöpfungsgeschichte [...] mit dem großen Hauptergebnis der modemen Biologie, der Entwicklungstatsache, vertraut gemacht«; Johannes Schlaf: Walt Whitman. Zur Einführung. Mein Verhältnis zu Walt Whitman, S. 436. In seinen Erinnerungen heißt es später: "Am bedeutungsvollsten wurde für mich [...], daß ich mit Haeckels Schriften [...] bekannt wurde " Johannes Schlaf: Aus meinem Leben, S. 18. Der Autor reklamierte deshalb für sich, durch seine literarischen Texte entscheidend zu einer ethisch-religiösen Vertiefung des haeckelschen Monismus beigetragen zu haben; vgl. Johannes Schlaf: [Rez.:] Julius Hart: Die neue Welterkenntnis. In: Stimmen der Gegenwart 3 (1902), S. 91.

Schlaf lobte Langbehns Schrift Rembrandt als Erizieber (1890) später als "Tat eines neuen synthetischen Geistes" und gestand rückblickend ein, daß ihm dieses Buch schon bei seinem Erscheinen sim geheimen manch schönes Herzklopfen« verursacht habe; Johannes Schlaf: Christus und Sophie. Wien/Leipzig. Akademischer Verlag 1906, S. I.

In der fingierten »Einleitung des Übersetzers» zum Band Papa Hamlet wird darauf hingewiesen, daß der vermeintliche Autor der Texte seine lyrischen Erstlingsversuche win den Seziersälen der Anatomie verfaßtu habe; Amo Holz/Johannes Schlaf: Papa Hamlet/Ein Tod, S. 16. Und so wie die "Anatomen« der Gegenwart „Dichter» seien, so seien auch »hihre Dichter Anatomen«; ebd., S. 17. 
gend als Verfasser meist kurzer, narrativer Texte hervorgetreten. ${ }^{67}$ Die sungebundener Rede hatte er dabei wegen ihres geringen Grades an ästhetischer Normierung privilegiert, der ihr nicht nur größere sLebensnäher zu ermöglichen, sondern auch den weitesten Darstellungsradius zu sichern schien. Der Lyrik war zwar ein Existenzrecht zugestanden, doch hatte das nicht zur Folge, daß Schlaf selbst sich dieses Ausdrucksmodus bedient hätte. Wenn er sich mit Versdichtung auseinandersetzte, dann geschah dies im üblichen Argumentationsrahmen naturalistischer Gattungstheorie, etwa aus Anlaß einer Rezension neuerer Gedichtanthologien. Gefordert wird, wie in vergleichbaren Verlautbarungen anderer naturalistischer Autoren auch, eine naturnahe, ungekünstelte Realitätswiedergabe, die sich im Kontext der Lyrik am ehesten durch die Verwendung unprätentiöser Sprache und den Einsatz freier Rhythmen erreichen lasse, was etwa Liliencrons Freiversgedicht Betrunken mustergültig zeige:

Die anderen xdichten،. Man merkt, wie man sich vorher zurecht geräuspert und eine Feiertagsmiene aufgesteckt hat. Man merkt es an dem sonntagnachmittaglichen Pathos. Der natürliche Wert des Wortes war zu schlicht und schlecht. Es mußte ein übriges gethan und das gute Naturwort in die Länge und Breite gezogen werden wie ein Stück Gummi, man mußte es aufgehen lassen wie einen Pfannkuchenteig. Um eine Ideec, um eine Pointe oder ein Pointchen herum wurden Strophen, Verse und Reime aufgebaut oder eine wilde, dunstige Ametrik geballt.

Nichts von alledem hier. Jedes Wort hat seinen schlichten, natürlichen Prosawert behalten. Keine pythisch-verworrene Fabuliererei, kein Kothurn jedem einzigen und harmlosesten Wort untergeschnallt. Das kann jederzeit und jedernorts so gesprochen werden, wie es dasteht und der simpelste Mensch kann es kapieren: und doch ist es Poesie, reinste, köstlichste Poesie und reichstes Leben. ${ }^{68}$

Erst im Lauf der neunziger Jahre begann Schlaf allmählich die Gestaltungsmöglichkeiten der Lyrik für seine eigene Textproduktion zu entdecken, wobei ihn auch jetzt nur reimlose, metrisch ungeregelte Gedichte interessierten. Als Anreger und Vorbildfigur fungierte Walt Whitman, der gleichermaßen literarisch wie ideologisch strahlkräftig auf Schlaf wirkte. Hier fand der deutsche Autor nicht nur jenen vitalistischen Biologismus vor, der ihm als Leitbild für die Entwicklung eines eigenen naturreligiösen Monismus diente, bei seinem amerikanischen Kollegen begegnete ihm auch genau das souveräne Sich-Absetzen von tradierten Dichtungskonventionen, ${ }^{69}$

67 Genannt seien hier Texte wie Papa Hamlet, Ein Tod (beide gemeinsam mit Amo Holz; 1889), Ein Dacbstubenidyll Novellistische Skizze (1890) und Die Geburt (1892). Daneben hatte Schlaf noch das "Drama in drei Aufzügena Meister Oelze (1892) publiziert.

Johannes Schlaf: Neue deutsche Lyrik. In: Freie Bühne für den Entwickelungskampf der Zeit 3 (1892), S. 858.

69

So heißt es etwa in Whitmans biographisch-poetologischem Schlüsseltext $A$ Backward Glance o'er Traveled Roads (1891) selbstbewußt über die eigene Dichtung: "I abandon'd the conventional themes [...]: none of the stock ornamentation, or choice plots of love or war, or high, exceptional personages of Old-World song; nothing, as I may say, for beauty's sake - no 
das ihm selbst so wichtig war. Von dessen herausragender Bedeutung für die moderne Literatur und Kultur in Europa zutiefst überzeugt, machte es sich Schlaf zur Lebensaufgabe, den bis dahin geringen Bekanntheitsgrad Whitmans durch Essays, Rezensionen $^{70}$ sowie eine eigene Auswahlübersetzung ${ }^{71}$ seines Hauptwerks, der Leaves of Grass (Erstausgabe 1855; vielfach erweiterte rdeath-bed edition 1891), nachhaltig zu steigern. Er stilisierte ihn dazu kurzerhand zum "Dichter-Propheten ${ }^{72}$ und behauptete, daß dessen Lehre noch wweitaus zeitgemäßer" ${ }^{73}$ sei und seine literarischen Errungenschaften noch größere Tragweite besäßen als die Nietzsches. ${ }^{74}$ Auf diese Weise wurde er zum eigentlichen Begründer und zugleich "Hauptvertreter des deutschen Whitmankults« ${ }^{75}$ um 1900.

Schlaf deutete den amerikanischen Autor dabei als Vertreter einer smodernen Dichtung im Sinne der naturalistischen Forderungen nach Realitätsnähe, wissenschaftlichem Erkenntnisanspruch und Überwindung formaler ästhetischer Reglementierungen. ${ }^{76}$ Und tatsächlich legen Selbstaussagen wie: »the New World needs

legend, or myth, or romance, nor euphemism, nor rhymers Walt Whitman: Complete Poetry and Collected Prose. [Ed. by Justin Kaplan.] New York: Literary Classics of the United States 1982 (= The Library of America 3), S. 658.

70 Die einzelnen Texte sind aufgeführt in Abschnitt II von Kafitz' Literaturverzeichnis; vgl. Dieter Kafitz: Johannes Schlaf - Weltanschauliche Totalität und Wirklichkeitsblindheit, S. 274-279.

71 Walt Whitman: Grashalme. In Auswahl übertragen von J. Schlaf. Leipzig. Reclam 1907 (= Reclams Universal-Bibliothek 4891-93). Law-Robertson bernerkt zu Recht, daß diese in vielem fehlerhafte und verzeichnende Übersetzung, die sich zudem stellenweise stark an frühere Übertragungen anlehnt, wdie erste volkstümliche Ausgabe in deutscher Sprache geworden ist«; Harry Law-Robertson: Walt Whitman in Deutschland. Gießen: Wilhelm Schmitz Verlag 1935 (= Gießener Beiträge zur deutschen Philologie 42), S. 22.

72 Johannes Schlaf: [Rez.:] Karl Knortz: Walt Whitman, der Dichter der Demokratie (Leipzig. Friedrich Fleischer 1899). In: Das litterarische Echo 2 (1899/1900), Sp. 65.

73 Novelien von Walt Whitman, ins Deutsche übertragen von Thea Ettlinger. Mit einem Geleitwort von Johannes Schlaf. Minden: J.C.C. Bruns' Verlag o.]. [1901], unpag.

74 Auch wenn er Nietzsche als "großen Sprachschöpferw anerkennt, kritisiert Schlaf an seinen Texten doch, daß sie "gespreizt, geziert, gewunden, posiert, bis ins innerste [sic] unnatürlich" seien; Johannes Schlaf: Der "Falk Nietzsche. Eine "Überwindungu. Leipzig. Verlag von Theod. Thomas 1907, S. 244 und 245. Sein Hauptvorwurf gegenüber Nietzsche lautet daher: „Er dichtet، noch zu viel, hat noch zu viel 'Festtagsgeberde « Ebd., S. 245. Derjenige Dichter, mwelcher uns von dem letzten Rest alter Symbolistik und Metapher, Trope und sonstigem besonderen Festtagskleid des Wortes, der uns resolut von den letzten Gespenstern der Metaphysik erlöst", sei Whitman: "Er schreibt die Sprache, die unverfälschte, der identisch gewordenen Moderne, die schlicht und recht sie selbst und so sein darf, wie sie istk Ebd., S. 245 und $245 \mathrm{f}$.

Walter Grünzweig: Walt Whitman: Die deutschsprachige Rezeption als interkulturelles Phänomen. München: Fink 1991, S. 51. Dabei ging er mit den Texten des amerikanischen Autors höchst selektiv um; so blendete er etwa die Themenbereiche Großstadt und Industrialisierung konsequent aus. 
the poems of realities and science and of the democratic average and basic equality, which shall be greater [than those of the Old World] ${ }^{77}$ es durchaus nahe, sie - bei allen fraglos bestehenden Unterschieden in der Poetik - als emphatische Bekenntnisse zu jenen Zielen zu verstehen, die Schlaf auch als die seinen ansah. Außerdem eilte Whitman der Ruf eines "Überwinders klassizistischer Formen ${ }^{78}$ voraus, auch wenn die damit verbundene Bewertung durchaus differierte. Dieser Nimbus rührt daher, daß die Leaves of Grass überwiegend aus Langzeilen bestehen, die z.T. über mehrere Zeilen geführt werden und so die angestammte Grenze zwischen Vers und Prosa unterlaufen. Infolgedessen charakterisierte schon der allererste deutsche Übersetzer Ferdinand Freiligrath Whitmans Lyrik als whythmische Prosa", die wunsere gesamte Ars poetica [...] all unsere ästhetischen Theorien und Kanons über den Haufen zu werfen droht ${ }^{79}$. Adolf Strodtmann, dem Herausgeber einer Anthologie von Gedichten amerikanischer Schriftsteller, schienen die mreimlosen, oft nur durch einen wilden Rhythmus die dichterische Form wahrenden Streckverse ${ }^{80}$, wie die Bezeichnung verrät, noch am ehesten mit Jean Pauls spoetischer Prosa vergleichbar. Julius Brand dagegen, der Verfasser eines frühen Aufsatzes über Whitman, betrachtete die Leaves of Grass schlichtweg als "grandiose Poesie " ${ }^{81}$ - trotz oder gerade wegen ihrer metrischen Regellosigkeit. In seiner Ambivalenz zwischen Lob und Tadel, Anerkennung und Unverständnis sehr bezeichnend für die frühe Whitman-Rezeption in Europa ist ein Vortrag von Knut Hamsun waus dem Jahre $1889{ }^{82}$, der allerdings erst 1900 in deutscher Übersetzung erschien. Zwar erkennt Hamsun die »litterarische Kühnheit«" ${ }^{83}$ der Leaves of Grass durchaus an; auch attestiert er Whitman sensualistisches Gespür. ${ }^{84}$ Gleichwohl bleibt das Werk selbst für ihn ein wwilder Karneval von Worten« und daher mals litterarisches Produkt ein Mißton ${ }^{85}$ :

Kommentar" zu den eigenen Texten des Autors lesen lassen: „Im Preis Whitmans werden die Ziele erkennbar, die Schlaf selbst anstrebte.» Wolfgang Riedel: „Homo Naturaw. Literarische Anthropologie um 1900, S. 127. Walt Whitman: Complete Poetry and Collected Prose, S. 664. Walter Grünzweig. Walt Whitman: Dic deutschsprachige Rezeption als interkulturelles Phänomen, S. 51.

79 Ferdinand Freiligraths sämtliche Werke in zehn Bänden, hrsg. von Ludwig Schröder. Bd. 7. Leipzig. Hesse o.J. [1907], S. 86 und 87.

80 Amerikanische Anthologie. Aus dem Englischen von Adolf Strodtmann. Erster Theil. Leipzig. Bibliographisches Institut o.J. [1870], S. 15. Julius Brand: [Walt Whitman.] In: Die Gesellschaft 5 (1889), S. 1818.

82 Knut Harnsun: Walt Whitman [1889]. In: Die Gesellschaft 16 (1900), Bd. 1, S. 26, Anm. Der Umstand, daß Hamsuns Text so wie vorher der Brands in der Gesellschaft erschien, belegt das nachhaltige Interesse der Naturalisten an Whitman.

Ebd., S. 31

84 
Der Verfasser selbst nennt dieses Werk Gesänge [...]. Es ist in Wirklichkeit [...] kein Gesang [...]; es ist in reiner Prosa verfaßt, ohne irgend eine Metrik und ohne Reim; das einzige, was an einen Vers erinnert, ist, daß eine Zeile ein, zwei, drei Worte haben kann, die nächste achtundzwanzig, fünfunddreißig bis - buchstäblich dreiundvierzig Worte. ${ }^{86}$

Was Hamsun hauptsächlich kritisiert, ist die rücksichtslose Überschreitung von Sprach- und Gattungsgrenzen, wie sie Whitman vollzieht:

Er vergißt in dieser Poesie, wieviel die Metrik vertragen und dulden kann, was ein Vers ohne Ende ist [...]. Wenn einer unserer heimischen demokratischen Dichter ein solches Poem verfaßte $[\ldots]$ und er brächte es einer Zeitung [...] - so glaube ich beinahe, man würde den Sänger anhalten, um seinen Puls zu fühlen und ihm ein Glas Wasser anzutragen; wenn er sich dagegen sträubte für verrückt zu gelten, würde man auf jeden Fall glauben, daß er einen schlechten Scherz gemacht. $^{87}$

Diese Stellungnahmen verdeutlichen, daß die europäische, in besonderem Maß aber die deutsche Whitman-Erstrezeption die Leaves of Grass dezidiert im Spannungsfeld von sPoesier und Prosa wahrnahm und das Werk als einschlägige Positionsmarkierung in der kontrovers diskutierten zeitgenössischen Auseinandersetzung um die Grenzen von Vers- und Prosadichtung verstand. Das dabei zum Ausdruck kommende Erstaunen über die ungewohnte, neuartig anmutende Struktur und die eigentümliche Sprachgebung der einzelnen Texte verdeckt allerdings, daß der Autor selbst sie gattungstypologisch mindestens in dreifacher Weise zu verankern suchte: Während der häufige Einsatz rhetorisch wirkungsvoller syntaktischer und lexikalischer Rekurrenzen klar die Sprachstrukturen biblischer Psalmen nachahmt ${ }^{88}$ und der Aufbau des Werks in einzelnen `Gesängen Gestaltungsmomente der antiken Epik aufruft, ${ }^{89}$ schließt die hymnisch-pathetische Diktion recht direkt an die - vor allem

\footnotetext{
Ebd., S. 24.

Ebd., S. 30.
}

87

88 Nach Bollobás war Whitman vor allem minspired by the syntactic aspect of the Bible's poetic techniques«; Enikö Bollobás: Tradition and Innovation in American Free Verse: Whitman to Duncan. Budapest: Akadémiai Kiadó 1986 (= Studies in Modem Philology 3), S. 107. Nicht zufallig kommt der amerikanische Autor in dem Band November Boughs explizit auf die Bedeutung der "Bible as Poetry zu sprechen; Walt Whitman: Complete Poetry and Collected Prose, S. 1139-1143. Vgl. in diesem Zusammenhang auch die Studie von James L. Kugel: The Idea of Biblical Poetry.

89 Schon Milch erkennt in den Laates of Grass eine »lyrisch-epische Mischform«; Wernex Milch: Amo Holz. Theoretiker, Kämpfer, Dichter. Berlin: Joachim Goldstein 1933, S. 16. Ähnlich Miller; vgl. James E. Miller: Leaves of Grass. America's Lyric-Epic of Self and Democracy. New York: Twayne / Toronto/Oxford/Singapore/Sydney: Marwell Macmillan 1992 (= Twayne's Masterwork Studies), S. 23. Bollobás bezeichnet das Werk als mnon-narrative epic«; Enikö Bollobás: Tradition and Innovation in American Free Verse: Whitman to Duncan, S. 72. Im $A$ Backward Glance o'er Traveled Roads genannten Appendix zu den Leaves of Grass erwähnt Whitman unter den Texten, die ihn nach eigener Aussage am stärksten angeregt haben, ausdrücklich die homerischen, altasiatischen und altdeutschen Epen: „I went over thoroughly the Old and New Testament, and absorb'd [...] Shakspere [sic], Ossian, the 
ja in Deutschland beheimatete - Tradition freirhythmischer Dichtung an. ${ }^{90}$ Das vergleichsweise späte Einsetzen der deutschen Wirkung von Whitmans CEuvre hatte darüber hinaus zur Folge, daß es im Zusammenhang mit Nietzsches philosophischen Schriften rezipiert wurde. So sahen die Zeitgenossen nicht nur Parallelen zwischen dem kulturkritischen Fundamentalismus beider Autoren, sie deuteten auch die spoetischer Formgebung ihrer Texte als verwandte Reaktionen auf den Zustand des Literatursystems im fin de siècle.

Betrachtet man die intensive Prägewirkung, die Whitmans Dichtung insgesamt auf Schlaf ausgeübt hat, so wird man zweifellos sagen dürfen, daß er durch »Menschenbild und Kunstauffassung« des amerikanischen Autors mwesentlich [...] beeinflußt ${ }^{91}$ worden ist. Dennoch läßt sich bei näherem Hinsehen eine aufschlußreiche Akzentverschiebung des Rezeptionsfokus feststellen, die in poetologischen Stellungnahmen ebenso zum Ausdruck kommt wie sie an der Werkentwicklung ablesbar ist. Zunächst nämlich fungierte Whitman für Schlaf weit mehr als ideologischer Gewährsmann denn als literarisches Vorbild. Der verstorbene Kollege wird von ihm anfangs vor allem als werster vollblütiger und großer Verkünder des neuen monistischen Geistes «" ${ }^{92}$ verstanden, mit dessen Hilfe sich der munselige Einfluß der mechanistischen Wissenschaft ${ }^{93}$ endlich überwinden lasse. Da sein mreligiöses, alles umspannendes Empfinden ${ }^{94}$ aber stets im Diesseitigen verbleibe - „Alles geht auf in einem einzigen, großen Kraft- und Lebensgefühl, das alles umspannt und umschließt. ${ }^{95}$-, werde mit einem Mal auch eine neue Synthese von Wissenschaft und

best translated versions I could get of Homer, Eschylus, Sophocles, the old German Nibelungen, the ancient Hindoo poems, and one or two other masterpiecesi; Walt Whitman: Complete Poetry and Collected Prose, S. 665. Die Ilias habe er dabei in »Buckley's prose version gelesen; ebd.

90 Es darf mittlerweile als erwiesen gelten, daß Whitman Novalis' Hymnen an die Nacbt rezipiert hat. Auf Parallelen zwischen beiden Autoren hat schon Bertz hingewiesen; vgl. Eduard Bertz: Der Yankee-Heiland. Ein Beitrag zur modernen Religionsgeschichte. Dresden: C. Reißner 1906. Unklar bleibt freilich, ob Whitman auch von der Prosafassung der Hymnen an die Nacht Kenntnis hatte. Jedenfalls wird hier abermals deutlich, auf welch oft schwer überblickbaren Wegen ursprünglich eigenkulturelle Traditionsimpulse zu einem späteren Zeitpunkt auf dem Weg der Rezeption fremdkultureller Muster in die Entwicklung einer Gattung eingespeist werden.

91 Dieter Kafitz: Johannes Schlaf - Weltanschauliche Totalität und Wirklichkeitsblindheit, S. 86 . Johannes Schlaf: [Rez.:] Karl Knortz: Walt Whitman, der Dichter der Demokratie, S. 66 Johannes Schlaf: Walt Whitman. Zur Einführung. Mein Verhältnis zu Walt Whitman, S. 437.

94 Johannes Schlaf: Walt Whitman. In: Freie Bühne für den Entwickelungskampf der Zeit 3 (1892), S. 987. Dieser Aufsatz wurde später nachgedruckt und erschien, durch zwei weitere Texte ergänzt, in Buchform; siche Johannes Schlaf: Walt Whitman. Lyrik des Chat Noir. Paul Verlaine. Leipzig. Spohr 1897. 
Religion möglich. Whitman erscheint unter diesem Blickwinkel als das werste große Genie einer neuen monistischen Religion, die sich aus dem intimsten Geist der modemen Naturwissenschaften erzeugt ${ }^{96}$. Seine besondere Leistung bestehe darin, dem monistischen Wirklichkeitskonzept literarische Form verliehen zu haben - ein Umstand, der Whitmans Dichtung allen expositorischen Texten überlegen mache. Die Leaves of Grass bewertet Schlaf deshalb als das wtiefste und einzigartigste poetisch-philosophische Werk des Jahrhunderts“" ${ }^{97}$.

Angesichts der immensen weltanschaulichen Orientierungsleistung des Amerikaners tritt der eigentlich künstlerische Innovationswert seines CEuvres eher zurück. Zwar erkennt Schlaf in den Leaves of Grass durchaus die "Macht der alten Urgesänge $^{98}$, im Grunde aber deutet er das Werk noch ganz im Licht der naturalistischen Lyriktheorie, wenn er die vermeintliche "Schlichtheit« von Whitmans müchterner Prosa« gegen die »Künste und Künsteleien « der »müden Decadence dieser Jahrhundertswende ${ }^{99}$ ins Feld führt: "Und doch ist alles so neu, schlicht und prosaisch bezeichnet. Keinerlei `Kunstmittek. [...] Diese Sprache ist so irdisch als nur möglich, oft mit fast amerikanischer Nüchternheit konstatierend, was ist. ${ }^{100}$ Zielperspektive ist nach wie vor die Überwindung konventioneller und als verbraucht empfundener Gestaltungsformen zugunsten eines sungeregelten`, maturnahen` Ausdrucks. Für Schlaf sind sdiese Gesänge [...] frei von allem, was man Kunst und Kunstmittel zu nennen pflegt, oder erweitern sie zu der Kraft und Kühnheit der bewegten $\mathrm{Na-}$ turd! ${ }^{101}$ Was in ihnen zum Ausdruck komme, sei letztlich nichts anderes als die sunmittelbar hervortretende Sprache der Natur selbst ${ }^{102}$ :

Ein unendlicher Rhythmus, eine unendliche Melodie. Wie der Sturm seinen ansteigenden und verebbenden und wieder ansteigenden Rhythmus hat, wie die Meereswellen ihn haben, die in der Sonnenwärme flimmernde Luft, der Gesang der Vögel, die unendliche Bewegtheit der Natur. ${ }^{103}$

96 Novellen von Walt Whitman, unpag. Dies geht soweit, daß Schlaf den amerikanischen Autor auch im sexualbiologischen Sinn als »Vertreter einer werdenden neuen Rasse" begreift; Dieter Kafitz: Johannes Schlaf - Weltanschauliche Totalität und Wirklichkeitsblindheit, S. 94. So heißt es in dem frühen Essay über Whitman: wMänner mit schönen, kräftigen Gliedem, blühend in Kraft und Gesundheit, schöne zeugungstüchtige Frauen mit wohlgestalteten, flinken Kindem, die gigantische Schönheit eines Hengstes sind seine Lust«; Johannes Schlaf: Walt Whitman [1892], S. 987.

97 Johannes Schlaf: Emst Häckels Wellräthsel In: Wiener Rundschau 3 (1898/99), S. 621.

98 Johannes Schlaf: Walt Whitman [1892], S. 980.

99 Johannes Schlaf: Walt Whitman: In: Neuland. Monatsschrift für Politik, Wissenschaft, Litteratur und Kunst $1(1896 / 97)$, Bd. 1, S. 7.

${ }_{100}^{100}$ Johannes Schlaf: Walt Whitman [1892], S. 980.

101 Johannes Schlaf: Walt Whitman [1896/97], S. 12.

102 Dieter Kafitz: Johannes Schlaf - Weltanschauliche Totalität und Wirklichkeitsblindheit, S. 87.

103 Johannes Schlaf: Walt Whitman [1892], S. 980. 
Schlaf nimmt an Whitmans Lyrik denn auch vorrangig ihre Unnormiertheit wahr, die er vor dem Hintergrund herkömmlicher Prosodie als Befreiung versteht.

Eine ähnliche Tendenz meint er bei seinen deutschen Kollegen Alfred Mombert und Richard Dehmel zu entdecken. ${ }^{104}$ Besonders ersteren zählt er wegen seiner eigenwilligen, ungeregelt wirkenden Versdichtungen zu den »Pionnieren [sic] einer

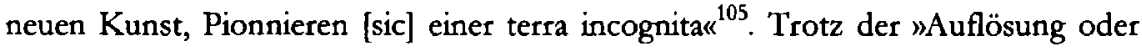
vielmehr [...] Umbildung der alten Vers- und Reimform«, die dazu führe, daß die walten festen Schemata und Muster [...] sich in freier und zwangloser Weise amalgamieren, herrsche skeine Willkür«:

Der ganze Proceß vollzieht sich vielmehr nach einem festen Gesetz. Es handelt sich nämlich bei dieser Revolution der lyrischen Form vor allem darum, mit intimster Treue die Stimmung und ihren natürlichen Rhythmus zu geben, diesen freien natürlichen Rhythmus, der, ich möchte sagen, der Rhythrnus der gesteigerten Nervenvibrationen [...] ist [...]. Es ist ein bunter, farbiger Wechsel der Nuancen, der Stimmungen und infolgedessen eine fröhliche Bewegtheit von Versmaß und Reim, wie sie bisher geradezu unerhört war.

Alle bisher conventionelle erstarrte Form, wie sie das lyrische Epigonenthum nach Goethe so sauber und mit so feiner Mühe herausgearbeitet, löst sich in freiem Rhythmus auf, und was früher freies Metrum genannt wurde und als solches in architektonischer Starrheit immer wieder Anwendung fand, gewinnt hier erst recht eine farbige wechselvolle Freiheit. ${ }^{106}$

Die sterra incognita«, von der Schlaf spricht, ist erkennbar die Übergangszone zwischen Vers und Prosa, die in der Moderne erstmals zum Explorationsfeld künstlerischer Bestrebungen werde. Das Ziel besteht allerdings nicht darin, die dichotomische Konstruktion des Literatursystems zu unterlaufen oder seine historisch und kulturell begründeten Prämissen zu hinterfragen, vielmehr geht es darum, die auf Grund konventioneller ästhetischer Normierungen voneinander getrennten Vertextungsmodi zu fusionieren. Der entscheidende Anstoß dazu gehe von der modernen Naturwissenschaft aus, die mit dem Monismus erstmals ein alle Seinsbereiche umfassendes, iganzheitlichesr Wirklichkeitsverständnis entwickelt habe. So wie nach monistischem Verständnis die neuzeitliche Subjekt/Objekt-Spaltung und der Dualismus zwischen Geist und Körper endgültig überwunden worden seien, müßten nun auch die gleichfalls obsolet gewordenen ästhetischen Demarkationslinien fallen.

104 "Dehmel, Mombert: so ungefähr kann einzig nach Nietzsche noch deutsche Lyrik aussehen [...] - Das heißt: wenigstens sprachlich-formal! Und - ungefähr! - " Johannes Schlaf: Der "Falla Nietzsche, S. 245.

${ }^{105}$ Johannes Schlaf: Neue Lyrik. Die Zeit (Wien), Nr. 193, 11.6.1898, S. 168.

106 Ebd. Schlaf bewegt sich mit der Annahme eines matürlichen Rhythmus» durchaus noch im Rahmen naturalistischer Kunsttheorie. So hatte etwa Heinrich Hart in seinem Aufsatz Die realistische Benegung. Ibr Ursprung ibr Wesen, ibr Ziel (1889) ausdrücklich erklärt, dem Naturalismus gelte sinnerer Gehalt [...] mehr als äußere Formu, und dies folgendermaßen erläutert: "EI ist darum nicht auf das Formlose versessen, aber er glaubt an eine Naturform, die mit dem Inhalt gegeben ist oder doch zwanglos aus ihm erwächst, ihm graut davor, den Gehalt in eine von außen hereingeholte Form hineinzuzwängen.» (MuD-N, S. 119) 
Das schlafsche Versöhnungsethos bezieht sich dabei weniger auf die einzelnen Subgattungen der Literatur, deren sich der Autor reichlich unbefangen weiter bedient, ${ }^{107}$ sondern richtet sich im wesentlichen auf die übergreifenden Ausdrucksmodi. Doch auch hier findet keineswegs eine völlige Vermischung statt. Statt dessen läßt sich eher eine gezielte Überschreitung auf je ein konkurrierendes Gestaltungsfeld hin beobachten. ${ }^{108}$ Das Drama wird gemäß Maeterlincks Poetik des ıIntimen ${ }^{109}$ in Richtung der Bewegungskünste Pantomime und Tanz geöffnet, während Versund Prosadichtung gegenseitig durchlässig gemacht werden. Entstehen soll jeweils eine shöhere, nämlich umfassendere, weniger differenzierte Kunstform, was die angestrebte Vereinigung der Gattungen faktisch als regressives Ideal erkennbar werden läßt. ${ }^{110}$ Eingebettet sind Schlafs ästhetische Anschauungen denn auch in eine geschichtsphilosophisch akzentuierte Kulturtheorie. Demnach werde sich künftig eine "völlig neue [...] Kultur ${ }^{111}$ herausbilden, deren Künste weltumspannende Geltung besitzen und sich gänzlich jenseits antiker und mittelalterlicher Muster bewegen. In den USA sei dieser Prozeß bislang am weitesten vorangeschritten. ${ }^{112}$ In Whitmans Dichtung meint Schlaf deshalb bereits jene Anzeichen ästhetischer Umgestaltung vorzufinden, die - wenngleich zunächst noch zögerlich - allmählich auch in Deutschland Platz greifen werde: "Auch wir beginnen die sLeier an die Wand zu hängen und münden in die Prosa, ins Identische, in die Wirklichkeit und ins Leben

${ }^{107}$ So finden sich im Titel oder Untertitel seiner Veröffentlichungen vielfach vertraute Textsortenbezeichnungen wie "Drama", "Roman«, "Novelle" und "Erzählung", aber auch minder gebräuchliche Termini wie "Geschichte« oder »Charakterbild» fallen aus dem zeitgenössischen Genrespektrum in keiner Weise heraus.

${ }^{108}$ Zu Überlappungsphänomenen zwischen verschiedenen Genres bzw. zwischen zu normierten Ausdrucksmodi geronnenen Schreibweisen war es ja schon in den gemeinsam mit Arno Holz verfaßten Textexperimenten gekommen. So nehmen die "Erzählpartien» in Der erste Schultag (1889) und Die papieme Passion (1890) iden Status von szenischen Anmerkungen anc; umgekehrt mist oder scheint die Familie Selicke radikal repischer Strukturc; Franz Norbert Mennemeier: Literatur der Jahrundertwende I, S. 232. Vgl. auch Reinhold Grimm: Naturalismus und episches Drama. In: R. G.: Nach dem Naturalismus. Essays zur modemen Dramatik. Kronberg i.Ts.: Athenäum 1978 (= Athenäum-Taschenbücher 2134), S. 28-54.

${ }^{109}$ Vgl. Annette Delius: Intimes Theater. Untersuchungen zu Programmatik und Dramaturgie einer bevorzugten Theaterform der Jahrhundertwende. Kronberg i.Ts.: Scriptor 1976 (= Hochschulschriften Literaturwissenschaft 19).

110 Mit der Annahme, daß Sprache, Musik und Tanz einst eine Einheit gebildet hätten, folgt Schlaf einem Argumentationsmuster, das von Karl Philipp Moritz und August Wilhelm Schlegel entwickelt und mit Blick auf die zeitgenössische Naturwissenschaft dann von Wilhelm Scherer positivistisch reformuliert und von seiner Fixierung auf die sgebundener Rede befreit worden ist; vgl. Wilhelm Scherer: Poetik, S. 9-13.

111 Johannes Schlaf: Walt Whitman. Berlin/Leipzig. Schuster \& Loeffler o.]. [1904] (= Die Dichtung 18), S. 11.

112 Zur Wahmehmung der USA um 1900 vgl. Deutschlands literarisches Amerikabild. Neuere Forschungen zur Amerikarezeption der deutschen Literatur. Hrsg. von Alexander Ritter. Hildesheim: Olms 1977 (= Germanistische Texte und Studien 4). 
ein; und dies ist eine notwendige, unausweichliche, logische, organische Konsequenz unserer Kulturentwicklung. « $^{113}$

Als Beleg für diese Vermutung dient ihm die Herausbildung freirhythmischer Gestaltungsformen, die sich nicht mehr an feste Zeilengrenzen halten. Hier sieht Schlaf eine neue Etappe der literaturgeschichtlichen Entwicklung erreicht, scheint damit doch ein Modus vorzuliegen, bei dem sich die unprätentiöse Nüchternheit der Prosa mit jener Intensivierung des Ausdrucks amalgamiert, die gewöhnlich der Lyrik zugeschrieben wird. »Abstrakte Begrifflichkeit«, die selbst »differenzierte technische wie politisch-soziale Zusammenhänge“ auszudrücken vermag, gehe auf diese Weise mit dem monistisch induzierten, "urtümlichen Pathos elementaren Naturgefühls ${ }^{114}$ eine bis dato unbekannte Verbindung ein. Im Ergebnis entstehe eine rorganische ${ }^{115}$ Prosa, die nach wie vor beansprucht, schmucklose, sungebundener Rede zu sein, zugleich aber doch als Medium eines "polyphon-emotionalen, naturalistischen freien Rhythmus " ${ }^{116}$ fungiert. Die neue "poetische Universalform " ${ }^{117}$, die Versdichtung und narrative Prosa miteinander vereint, stellt freilich auf shöherer Ebene nur wieder einen Zustand her, der schon am Anfang der Literaturgeschichte bestanden habe: eine snaturnahe، Ur-Kunst vor der Ausdifferenzierung in einzelne Funktionsbereiche ${ }^{118}$ und damit auch vor der Herausbildung ästhetischer Konventionen, die seitdem alle literarischen Hervorbringungen einem ssekundär-artifiziellen Regelschematismus« ${ }^{119}$ unterworfen hätten.

Dieses eigenwilliges Deutungskonstrukt amalgamiert monistische Einheitspostulate mit geschichtsphilosophischen Ursprungsphantasien und romantischem Utopismus: "Denn was Schlaf über Wesen und Form der Whitmanschen Vollendungsdichtung aussagt, deckt sich wenigstens teilweise mit Herders Deutung der elementarunmittelbar aus dem Gefühl geschaffenen Originalpoesieu ${ }^{120}$. Anders aber als Herder geht Schlaf nicht vom Primat der Poesie aus, sondern läßt die künstlerische Ent-

113 Johannes Schlaf: Walt Whitman [1904], S. 86.

114 Lothar Jegensdorf: Die spekulative Deutung und poetische Darstellung der Natur im Werk von Johannes Schlaf. Diss. (Masch.) Bochum 1969, S. 263.

115 Johannes Schlaf: Der »Fall Nietzsche, 245.

116 Johannes Schlaf: Die Vollendung des Naturalismus. In: Die Güldenkammer 2 (1911/12), S. 522.

117 Lothar Jegensdorf: Die spekulative Deutung und poetische Darstellung der Natur im Werk von Johannes Schlaf, S. 263 bzw. 264

${ }^{118}$ So nimmt Schlaf an, daß in der menschlichen Urzeit die einzelnen Ausdrucksformen noch eng miteinander verbunden gewesen seien: »Wir haben für die älteste Urzeit die völlige Einheit von Wort, Melos, Musik, Mimik und Tanz anzunehmen«; Johannes Schlaf: Das absolute Individuum und die Vollendung der Religion. Berlin: Osterheld \& Co. Verlag 1910, S. 553.

119 Lothar Jegensdorf: Die spekulative Deutung und poetische Darstellung der Natur im Werk von Johannes Schlaf, S. 261.

${ }^{120}$ Ebd., S. 262. 
wicklung vielmehr mit der Prosa beginnen, ${ }^{121}$ die direkt aus dem Akt sprachlichen Benennens selbst entspringe:

Das Wort aber ist bei alldem vor allem die namentliche Anrufung und Bezeichnung dessen, um was es sich im gegebenen Falle handelt. Und zwar die möglichst deutliche und verständliche Anrufung und Bezeichnung. Und ausserdem noch durchaus keine in einem späteren Sinne kunstgemässe, sondem die allergeläufigste und vertrauteste, pprosaisch unmittelbarste, wahrste, unverfälschteste, schlichteste; gemäss der Notwendigkeit und Aufrichtigkeit des emotionalen Zustandes. (Was übrigens bis heute je und je wesentlichste und edelste Eigenschaft jeder wahren Kunst gewesen und geblieben ist und auch stets bleiben muss!) ${ }^{\text {i22 }}$

Die in der Urzeit noch gegebene Polyphonie der Sprache sei jedoch im Lauf der Zeit mehr und mehr verlorengegangen und in einzelnen, voneinander separierten Ausdrucksregistem - den Gattungen, vor allem den lyrischen - kanalisiert worden. Die von den Naturalisten geforderte Durchbrechung überholter Konventionen stellt unter diesem Blickwinkel den Anfang eines grundlegenden ästhetischen Paradigmenwechsels dar, der im Endeffekt - gestützt auf die zeitgenössischen wissenschaftlich-naturphilosophischen Ganzheitslehren - einen künstlerischen Monismus begründen werde. Vorgezeichnet erscheint diese Utopie im frühromantischen Konzept der "progressiven Universalpoesie«, das ja ebenfalls auf eine totale Fusionierung der Genres und Kunstformen abzielt. ${ }^{123}$ Was freilich im Rahmen romantischer Poetologie Ergebnis eines potenzierten Reflexionsprozesses ist, bietet sich bei Schlaf als naive Rückkehr zu einem vorkantischen Erkenntnisstand dar. ${ }^{124}$ Denn nur eine vorkritische philosophische Position gestattet die gewünschte direkte Übertragung

${ }^{121}$ Die historische Ursprünglichkeit der Prosa war zuerst von Charles Batteux in seiner weitverbreiteten Schrift Les Beaux Arts réduit à un méme principe (1747) postuliert worden. Zum Argumentationszusammenhang und seinen Auswirkungen auf die ästhetischen Debatten vgl. Márcio Seligmann-Silva: Prosa-Poesie-Unübersetzbarkeit. Wege durch das 18. Jahrhundert und von den Frühromantikem bis zur Gegenwart. Diss. (Masch.) Berlin 1996, S. 163173, sowie Irmela von der Lühe: Natur und Natumachahmung. Untersuchungen zur Batteux-Rezeption in Deutschland. Bonn: Bouvier 1979 (= Abhandlungen zur Kunst-, Musikund Literaturwissenschaft 283).

122 Johannes Schlaf: Das absolute Individuum und die Vollendung der Religion, S. 554f.

123 In Friedrich Schlegels berühmt gewordener ,Definition، heißt es bekanntlich über das solcherart benannte Ideal: „Ihre Bestimmung ist nicht bloß, alle getrennte Gattungen der Poesie wieder zu vereinigen, und die Poesie mit der Philosophie und Rhetorik in Berührung zu setzen. Sie will, und soll auch Poesie und Prosa, Genialität und Kritik, Kunstpoesie und Naturpoesie bald mischen, bald verschmelzen, die Poesie lebendig und gesellig, und das Leben und die Gesellschaft poetisch machen«; Friedrich Schlegel: Kritische Schriften und Fragmente. Studienausgabe in sechs Bänden, Bd. 2, S. 114.

${ }^{124} \mathrm{Vgl}$. in diesem Zusammenhang Schlafs Aufsatz: Monismus und das Kantische Erkennen »a priori火 und wa posteriori火. Ein Beitrag zur Überwindung von Kants Kritizismus. In: Deutscher Frühling 1 (1908), S. 264-271, aber auch seine umfangreiche Abhandlung Das absolute Individuum und die Vollendung der Religion (1910). 
ontologischer Sachverhalte auf die Kunst - "Naturgesetze sind demnach [...] zugleich ästhetische Gesetze " ${ }^{125}$ - und ermöglicht es beispielsweise, die Prosa zum einzig adäquaten literarischen Ausdrucksmedium des sunendlichen Rhythmus ${ }^{126}$ der Natur zu erklären.

Poetologisch bleibt Schlaf damit weitgehend auf dem Boden naturalistischer Lyriktheorie. Den entscheidenden Schritt über deren Prämissen hinaus tut er schließlich erst, als er - bestätigt durch das Beispiel Whitmans - offen eine Pathetisierung der Prosa fordert. Erstmals taucht dieser Gedanke in dem Bändchen In Dingsda auf, wo wehmütig-ironisch das naturalistische Selbstverständnis mit dem emphatischen Dichterbild der Vergangenheit kontrastiert wird:

Früher gab es eine Zeit, wo der Dichter der Seher war, Prophet, Priester.

[...]

Wir lächeln darüber, wir, les soldats les plus convaincus du vraic, wir Arbeiter und Experimentatoren, Positivisten, Objektivisten und Dokumentensammler in unserer werktagstolzen Bescheidenheit.

[...] Wir sind so schlicht, und jedes Pathos macht uns lachen. ${ }^{127}$

Und im selben Jahr heißt es anerkennend über die Leoves of Grass. wDiese Sprache ist so irdisch als nur möglich, oft mit fast amerikanischer Nüchternheit konstatierend, was ist. Und doch hat sie ihr Pathos, überwältigend und hinreißend, wie es nur eins gegeben hat. ${ }^{128}$ Vier Jahre später lobt Schlaf an Whitmans Texten dann ausdrücklich wihre Kraft und ihr Pathos « ${ }^{129} .1898$ schließlich plädiert er rundheraus für ein wneues Pathos" in der Literatur, das den "müden, anämischen Decadence-Charakter ${ }^{130}$ der symbolistischen Dichtung vertreiben soll. Freilich ist nicht das "sonntagnachmittagliche Pathos der Gründerzeitlyriker gemeint, das sich dadurch auszeichnet, daß in einem durch die Regeln der Prosodie vorgegebenen Rahmen - und weitgehend unabhängig vom Inhalt des Mitgeteilten - möglichst viele rhetorische Figuren auf engstem Raum untergebracht werden, vielmehr soll eine möglichst snatür-

${ }^{125}$ Lothar Jegensdorf: Die spekulative Deutung und poetische Darstellung der Natur im Werk von Johannes Schlaf, S. 222. Im Gegenzug zu den von Haeckel propagierten »Kunstformen der Naturu sollen gewissermaßen Naturformen der Kunst gefunden werden.

Johannes Schlaf: Walt Whitman [1896/97], S. 12.

127 Johannes Schlaf: In Dingsda [1892], S. 78.

128 Johannes Schlaf: Walt Whitman [1892], S. 980.

129 Johannes Schlaf: Walt Whitman [1896/97], S. 12.

130 Johannes Schlaf: Neue Lyrik, S. 169. Schlaf konstruiert in diesem Zusammenhang sogar eine Verbindung zwischen nationaler Zugehörigkeit und sprachlicher Präferenz. So zeigt er sich davon überzeugt, daß sich ndas Pathos bei uns Deutschen [...] wohl überhaupt auf die Dauer nicht wird unterdrücken lassenc: "Wir haben einmal einen unüberwindlichen Hang zum Getragenen, zur gehobenen Redeweise; auch die Frömmigkeit unseres Nationalcharakters, das Merkmal unserer Rasse, macht sich hier wieder mit all seiner Naturnothwendigkeit geltend. « Andere Nationen verfügen demnach nicht über diese Affinität. So würde etwa bei sden Franzosen [...] das Pathos immer wieder leicht in Rhetorik umschlagenc, ebd. 
lich wirkende, prosanahe Art des Ausdrucks gefunden werden, welche die Schönheit einer monistisch gedeuteten Natur sprachlich adäquat zu gestalten vermag. Als Autoren, die ein solches mneues Pathos« literarisch bereits umgesetzt hätten, werden Whitman, Nietzsche, Mombert sowie Carl Spitteler genannt.

Die Pathetisierung des matürlichen Ausdrucks steht dabei im Kontext des ursprünglich "sakralen Charakters« der Literatur, zeigt Schlaf sich doch davon überzeugt: "Kunst hat ihren Ursprung mit der Religion “ ${ }^{131}$. Benenne alltagsweltliche Sprache lediglich das, was ist, so könne literarische Rede den Akt verbaler Deixis noch steigern; ihre primäre Funktion sei deshalb die kultische Feier des kosmischen Seinszusammenhangs. Die enge Bindung von Literatur und Religion sei jedoch mit der Zeit verlorengegangen. Dies hänge mit der - verhängnisvollen - Ausdifferenzierung der Sozialstrukturen zusammen. So habe die zunehmende Etablierung von »Kunstregeln« und die allmähliche Herausbildung von wästhetisch wissenschaftlichen Systemen« schließlich eine »Abbindung der Künste von der Religion « ${ }^{132}$ bewirkt. Erst die moderne Naturwissenschaft eröffne wieder die Aussicht auf eine wwirklich religiöse Kunst « ${ }^{133}$, die aber nur entstehen könne, wenn die Ästhetik zu ihren Anfängen zurückkehre. Den entscheidenden Schritt habe in diesem Zusammenhang der Naturalismus gemacht, der die Herrschaft des bisherigen literarischen Normensystems gebrochen und die Sprache aus den Fesseln der normativen Kunstlehre befreit habe. Damit freilich sei verfahrenstechnisch auch ein ultimativer Fluchtpunkt der ästhetischen Entwicklung markiert, denn: "Es ist undenkbar, dass die Dichtkunst über den Freivers oder über die naturalistische Prosa im wesentlichen hinaus kann. ${ }^{134}$ Immerhin aber biete die Rhetorisierung der Sprache die Möglichkeit, duch die wirkungsvolle Nutzung aller neugewonnenen Freiheiten an die einstige kultische Funktion von Literatur wieder anzuknüpfen und auf diese Weise die ultimative Form künstlerischen Ausdrucks, die »Endkunst der Menschheit ${ }^{135}$ zu verwirklichen.

Aufgabe des modernen Schriftstellers ist es demnach, das "Pathos der Natur ${ }^{136}$ ästhetisch zu vermitteln. Dementsprechend hat Schlaf spätestens seit Mitte der neunziger Jahre seine eigene dichterische Produktion an dem Leitbild einer pathetisierten Prosa ausgerichtet. Erstmals erprobt wird dieses Konzept in der Textreihe Frübling. die nach dem Vorabdruck eines Abschnitts in Bierbaums Modermem Musen-Almanach 1896 dann vollständig in Buchform erschien und in einigen Kreisen der literarischen Öffentlichkeit als definitive "Abkehr vom konsequenten Naturalismus gefeiert « ${ }^{137}$

\footnotetext{
131 Johannes Schlaf: Das absolute Individuum und die Vollendung der Religion, S. 552.

132 Ebd., S. 557

133 Ebd., S. 572

134 Ebd., S. 581.

135 Ebd., S. 573.
}

136 Johannes Schlaf: Neue Lyrik, S. 169.

137 Harry Law-Robertson: Walt Whitman in Deutschland, S. 63f. Deutlichsten Ausdruck fand diese Einschätzung in einem begeisterten Brief Richard Dehmels an Bierbaum vom 13. Juli 
wurde. Der Band besteht aus insgesamt 15 einzeln betitelten Texten - der längste erstreckt sich über 29 Druckseiten, die kürzesten umfassen nur eine halbe Seite -, die diverse Verlaufsformen zwischen Vers und Prosa gestalten. ${ }^{138}$ So gibt es sowohl Prosatexte mit mehr oder minder deutlicher narrativer Struktur (die Titelerzählung Frübling, Zwielicbt, Das Lied) wie auch freirhythmische Versgedichte (Schönbeit, Im Heidekraut, Unter den tiefen dunken Wolken, Das dunkle Tor, Was es doch ist!, Nachthimmel) und regelrechte Hybridtexte (Am Graben, Die Vehikel, Andacht, Der Tod, Glück, Mondlicht. Eine Phantasie), bei denen eine Gattungszuordnung davon abhängt, ob man die einzelnen Segmente als Kurzprosaabschnitte oder als Langzeilen nach dem Muster von Whitmans Leaves of Grass ansehen möchte. Erkennbar knüpft Schlaf hier an Verfahrensweisen seiner deutschen Kollegen an: Das Muster der Mischpublikation von Vers- und Prosatexten war ihm aus Liliencrons Veröffentlichungen, ${ }^{139}$ durch Bierbaums Erlebte Gedichte ${ }^{140}$ und Croissant-Rusts Gedichte in Prosa, ${ }^{141}$ aber auch von

1893, den dieser kurzerhand zusammen mit Schlafs Text abdruckte; vgl. Modemer MusenAlmanach auf das Jahr 1894. Hrsg. von Otto Julius Bierbaum. Ein Jahrbuch deutscher Kunst. Zweiter Jahrgang. Mit Beiträgen der hervorragendsten Vertreter des modernen deutschen Schrifttums. München: Albert o.J. [1893], S. 269-279. Ähnlich emphatisch äußert sich Dehmel am 16. Juli gegenüber Henri Albert; dort heißt es über Frühling. "Ich halte es für eine Lebenswende der ganzen modernen Poesie, eine Wende zu neuem Glauben, neuer Kraft, neuer Gesundheit. Ich habe geweint, so hat es mich erschüttert." Eine deutschfranzösische Brieffreundschaft. Richard Dehmel - Henri Albert. Briefwechsel 1893-1898. Hrsg. und kommentiert von Catherine Krahmer. Herzberg. Verlag Traugott Bautz 1998 (= bibliothemata 16), S. 85 . Vgl. in diesem Zusammenhang auch die Stellungnahmen von Autorenkollegen in dem Band: Johannes Schlaf. Leben und Werk. Hrsg. von Ludwig Bäte und Kurt Meyer-Rotermund. Querfurt: R.K. Jaeckel o.J. [1933].

138 Dehmel bezeichnet Schlafs Frühling in einem Brief an Henri Albert vom 16. Juli 1893 als "prosaisches Lyrikon«; Eine deutsch-französische Brieffreundschaft. Richard Dehmel Henni Albert. Briefwechsel 1893-1898, S. 85. Auch meint er darin "Jean Paul Reminiszenzen « zu erkennen, was sich nur auf die formale Struktur der Texte beziehen läßt und daher als Anspielung auf die "Streckverse« zu werten ist; ebd., S. 86, Anm. 1. Riedel stellt Schlafs Band dagegen in die »Eklogentradition 4 und verstcht die darin enthaltenen Texte als »modemee Idyllen«; Wolfgang Riedel: „Homo Naturak. Literarische Anthropologie um 1900, S. 123. Von hier aus wird auch der Rückgriff auf die Vertextungsformen spoetischer Prosa im 18. Jahrhundert verständlich, vgl. hierzu etwa John L. Hibberd: Salomon Gessner's Idylls as Prose Poems.

139 Nicht zufälig sah Schlaf die Adjutantenritte als Liliencrons "vollendetstes Werk« an; Johannes Schlaf: Detlev von Liliencron. Ein litterarisches Bild. In: Die Gesellschaft 3 (1887), S. 227.

140 Der Abdruck der Textreihe Frübling in Bierbaums Periodikum läßt nicht nur stark vermuten, daß Schlaf die Veröffentlichungen dieses Autors kannte, sondern indiziert darüber hinaus auch eine gewisse Affinität zu dessen ästhetischem Programm. Dies trifft im übrigen auch auf die Thematik zu. So hat auf Schlaf mit Sicherheit die Naturemphase Bierbaums vorbildhaft gewirkt, dessen Band Erlebte Gedichte ja gleichfalls mit einem Frühling betitelten Text beginnt. Zu den vielfältigen semantischen Facetten, die der Begriff »Frühling um die 
Dauthendeys Ultra Violett ${ }^{142}$ oder Dehmels Aber die Liebe. Ein Ehemanns- und Menschenbuch $(1893)^{143}$ vertraut, und die einschlägigen Experimente mit dem Gattungsstatus verweisen ebenfalls klar auf die Anregerfunktion dieser Autoren. ${ }^{144}$

Was Schlaf allerdings von den Vertretern der Münchner Moderner markant unterscheidet, ist der enge Bezug zwischen den einzelnen Texten des Bandes, lassen diese sich doch als eine Art Zyklus verstehen. Textuelle Zyklenbildung freilich war bislang nur im Bereich der Verslyrik üblich, begegnete allenfalls noch gelegentlich im Rahmen novellistischer Narrativik. Indem Schlaf nun Vers- und Prosatexte unterschiedlichster Länge miteinander kombinierte und zu einem größeren Ganzen zusammenschloß (nicht zufällig erschien Frübling ohne Gattungsbezeichnung), entstand ein einzigartiges Gebilde jenseits der Gestaltungsgrenzen gebräuchlicher lyrischer wie narrativer Genres. Der Autor führte mithin eine neue ästhetische Strukturierungsweise in die deutsche Literatur ein, die sich durch die eigenwillige Verschränkung von Kurz- und Langform auszeichnet. Frübling gleicht einer Kippfigur, die - je nach Betrachtungsweise - entweder eine Folge von eigenständigen, thematisch locker miteinander verknüpften Vers- und Prosagedichten oder eine mehrfach in sich parzellierte Textstruktur spoetischer Prosa zu erkennen gibt. Gerade im Hinblick auf die textuelle Amalgamierung lyrischer und narrativer Elemente und den Aufbau eines solchen Mischgebildes hat wohl nicht zuletzt Nietzsches Zaratbustra inspirierend gewirkt. Daneben konnte Schlaf natürlich auch in der französischen Literatur weitere Anregungen für sein Textmodell finden. Genannt seien hier nur die Bände Gaspard de la nuit. Fantaisies à la manière de Rembrandt et de Callot (1842) von Aloysius Bertrand und Livre de Jade. Poésies traduites du chinois (1867) von Judith Wal-

Jahrhundertwende aufweist, gehören vor allem Vorstellungen von Ursprung bzw. Neubeginn und Undifferenziertheit.

141 An dieser Stelle sei noch einmal an Schlafs Besprechung von Croissant-Rusts Band Lebensstïcke hingewiesen; vgl. Johannes Schlaf: Münchener Dichtung. Schlafs persönlicher Kontakt mit führenden Vertretem der Münchner Moderne datiert von Anfang der neunziger Jahre. So ist in seinen Erinnerungen zu lesen: „Es war im Sommer 1892, daß ich von der Münchener sLitterarischen Gesellschaftu die Einladung erhielt dort vorzutragen. [...] Ich machte bei dieser Gelegenheit die Bekanntschaft Michael Georg Conrads [...]; auch die von Otto Julius Bierbaum, der Dichterin Anna Croissant-Rusta. Besonders erwähnenswert ist in diesem Zusammenhang die Begegnung mit jenem Autor, der kurz zuvor radikale Thesen zur Zukunft der Versdichtung formuliert hatte: "Auch mit Max Halbe traf ich zusammenu. Schlaf erwähnt sogar, daß er wvierzehn sehr angenehme Tagew bei ihm und seiner Familie verbracht habe; Johannes Schlaf: Aus meinem Leben, S. 40.

142 Texte aus Ulita Violett erschienen sowohl im Jahrgang 1893 (S. 261-263: Auferstehung) als auch im Jahrgang 1894 des Modernen Musen-Almanachs (S. 205f.: Gesänge der Düffe).

143 Dieser Band ist ein Liliencron verpflichtetes compositum mixtum, das Lyrik mit längeren Prosatexten (S. 19-56: Die drei Schuestem. Eine Geschichte mit Zuhörerm; S. 121-138: Hamburger Lästerbrief; S. 141-145: Gevissen) untermengt.

144 Die Technik der Kleinschreibung des Versanfangs begegnet zu dieser Zeit - außer bei Dehmel - vor allem bei Croissant-Rust; vgl. Kapitel III/3b. 
ther (Pseudonym für Judith Gautier) - Publikationen mithin, deren Texte immer wieder als poèmes en prose rezipiert worden sind, ${ }^{145}$ obwohl sie sich strenggenommen eher in der Tradition der sprose poétiquer bewegen. ${ }^{146}$

Vergleichsweise schwach ausgeprägt sind dagegen Züge, die auf eine Orientierung an den Leaves of Grass hindeuten. Obwohl er in seinen Essays über Whitman die igroßen dithyrambischen Züge ${ }^{147}$ des Werks besonders hervorhebt und die wdunklen prächtigen Rhapsodieen des Dichters « ${ }^{148}$ bewundert, hat Schlaf in Frühling weder die Struktur von dessen Texten nachgeahmt noch die stilistischen Mittel dieses Autors in größerem Ausmaß übernommen. Und der nicht selten titanische Gestus des amerikanischen Kollegen ist bei ihm einer bürgerlichen Provinzidyllik gewichen, die den behaglich-regressiven Rahmen für die privatistischen Einheitsphantasien des erlebenden Ich bildet. ${ }^{149}$ Auch was Lexik und Syntax angeht, ist in diesem Band - entgegen anderslautenden Stimmen in der Forschung - ein wirklich wdithyrambischer Tonfall ${ }^{150}$ nicht zu erkennen. Wohl aber wird die Sprache - z.T. kaum merklich, z.T. sehr nachhaltig - pathetisiert. In Kombination mit Schlafs ausgeprägter "parataktischer Reihungstechnik ${ }^{151}$ erzeugen die Tendenz zu "Nominalisierung" und "prunkhafter Wortausschmückung", zur "Aufhebung von Wortartgrenzen«, zur "Bildung von Wortkomposita und zur lexikalischen "Vermeidung ${ }^{152}$ begrifflicher Eindeutigkeit einen moderat 'gehobenen Stil, der sich zwar von der Alltagssprache mehr oder minder deutlich abhebt, gleichwohl aber nicht über jenes Maß an Rhetorisierung hinausgeht, dem man auch andernorts im Rahmen spoetischer Prosar begegnet.

$145 \mathrm{Vgl}$. in diesem Zusammenhang Friedrich Banner: Aloysius Bertrands Gaspard de la Nuit als Wortkunstwerk; Fritz Nies: Poesie in prosaischer Welt. Untersuchungen zum Prosagedicht bei Aloysisus Bertrand und Baudelaire; Suzanne Bernard: Le poème en prose jusqu'à nos jours, S. 49-73 und 335-342. Marvin Newton Richards: Without Rhyme or Reason. Aloysius Bertrand and the Dialectic of the Prose Poem; sowie Nathalie Vincent-Munnia: Du poème en prose comme art de la magie chez Aloysius Bertrand. Für die zeitgenössische Konjunktur des Litre de Jade ist im wesentlichen die Nennung des Buchs in Huysmans' $\dot{A}$ rebours (1884) verantwortlich; vgl. das entsprechende Zitat in Kapitel III/5a.

146 Die spoetische Prosa freilich amalgamierte sich auch in Frankreich mehrfach mit dem neuen Gattungsmuster Prosagedicht und brachte dadurch eigentümliche Zwitterformen hervor.

147 Wiener Rundschau 3 (1898/99), S. 618f.

148 Johannes Schlaf: Walt Whitman [1896/97], S. 7.

149 Es muß deshalb nachdrücklich Law-Robertson zugestimmt werden, der schon früh bemerkt hat: "Zwischen den farbenprächtigen Kleinmalereien in Frühling und dem souffle impétueux، der Verse Whitmans besteht ein sehr großer Unterschied. « Harry Law-Robertson: Walt Whitman in Deutschland, S. 63.

150 Dieter Kafitz: Johannes Schlaf - Weltanschauliche Totalität und Wirklichkeitsblindheit, S. 108 und 110.

151 Lothar Jegensdorf: Die spekulative Deutung und poetische Darstellung der Natur im Werk von Johannes Schlaf, S. 275.

152 Ebd., S. 268, 285, 296, 299 und 291. 
Während Frühling durch eine gänzliche stilistische Einebnung des Unterschieds zwischen Vers- und Prosarede zugunsten eines Pathos mittlerer Ebene charakterisiert ist, zeichnet sich der 1899 veröffentlichte Band Helldunkel ${ }^{153}$ durch einen partiellen Rückgriff auf lyrische Vertextungsmuster aus. Hier begegnen erstmals seit Schlafs Erstlingsveröffentlichungen Mitte der achtziger Jahre wieder Versgedichte mit strophischer Gliederung und traditionellem Reimschema. Diese stehen neben freirhythmischer Lyrik und vom Druckbild auf den ersten Blick wie Prosa wirkenden Texten, deren - bis zu sieben Zeilen umfassende - Absätze sich jedoch dadurch, daß sie durchweg eingerückt sind, als Langzeilen zu erkennen geben. Die Stilebene des gesamten Bandes, besonders aber der Prosagedichte, ist gegenüber Frühling merklich erhöht, was sich an der Wortwahl wie auch an der Syntax ablesen läßt. Zahlreiche Interjektionen und eine Vielzahl von Ausrufe- und Fragezeichen bestätigen den Eindruck, daß Schlaf sich hier jener Spielart des genus sublime bedient, die besonders im Kontext der freirhythmischen Dichtung vielfältige Verwendung gefunden hat. ${ }^{154}$ Im Vergleich dazu wirkt die Diktion der herkömmlicher Lyrik angenäherten Versgedichte deutlich nüchterner. Doch anders als Bierbaum in seinen $E r$ lebten Gedichten zielt Schlaf offensichtlich nicht auf eine Kontrastierung verschiedener Sprachebenen ab, sondern will eher ein Verlaufsspektrum sdichterischer Rede textuell umsetzen. Die regelmäßig gegliederten Versgedichte markieren dabei das eine Ende der Skala; hier genügen bereits Strophik und das konventionelle Reimschema, um eine slyrischer Wirkung zu erzielen, weshalb der Autor über diese Poetizitätssignale hinaus sehr sparsam mit Kunstmitteln umgeht. Daneben finden sich freirhythmische Gebilde mit sehr ungleicher Verslänge - Das Wort, Die Schaumkrautwiese, Im tiefen Grund (Fragment) -, wobei der Umfang des einzelnen Verses im allgemeinen zwei Druckzeilen nicht überschreitet. Der Einsatz von Reimwörtern ist bei diesen

153 Das Oxymoron "Helldunkelw fungierte um die Jahrhundertwende nachgerade als Kennwort; so veröffentlichte Heinrich von Schullem einen Band HelldunkeL Bilder und Lieder (Wien: Lesk \& Schwidemoch 1892), und der unter dem Pseudonym Bodo Wildberg publizierende Heinrich Louis von Dickinson-Wildberg brachte einen - immerhin von Rilke erwähnten (vgl. R-SW V, S. 315) - Gedichtband mit dem Titel Helldunkle Lieder (Dresden: Pierson 1897) heraus. Kafitz spricht deshalb zu Recht von einer "Symbolfarber; Dieter Kafitz: Johannes Schlaf - Weltanschauliche Totalität und Wirklichkeitsblindheit, S. 113. Langbehn hatte ein Kapitel seines Buches Rembrandt als Erzieher so überschrieben, und Schlaf selbst ließ seinen im selben Jahr wie die Gedichtsammlung Helldunkel erschienenen Band Stille Welten. Neue Stimmungen aus Dingsda in eine Episode münden, in der das erzählende Ich eine mystische Erfahrung macht und in diesem Zusammenhang einen transitorischen $\mathrm{Zu}-$ stand der All-Einheit erlebt, wdas weder Dunkle noch Helle, das Weder-noch, das dennoch ein Sowohl - als Auch ist«; Johannes Schlaf: Stille Welten. Neue Stimmungen aus Dingsda. Berlin: F. Fontane \& Co. 1899, S. 233.

${ }^{154}$ Vgl. hierzu Emst Busch: Stiltypen der deutschen freirhythmischen Hymne aus dem religiösen Erleben. Frankfurt a.M.: Diesterweg 1934 (= Frankfurter Quellen und Forschungen zur germanischen und romanischen Philologie 6) 
Texten stark zurückgenommen; zugleich aber erscheint die Stilhöhe merklich angehoben. Auf ähnlichem rhetorischem Niveau bewegen sich die dezidiert als Gedichte in Prosaform gestalteten Langzeilentexte (Die Eine, Das Kinderland, Auf der Düne, Das Lied vom Tode). In ihnen wird der Verzicht auf herkömmliche lyrische Gestaltungsmittel zusätzlich syntaktisch kompensiert: Vor allem die ausgiebige Verwendung des parallelismus membrorum - zusätzlich unterstützt durch Wortrekurrenzen und Anaphern - sorgt für die gewünschte hymnische Feierlichkeit.

Natürlich verlaufen die Übergänge zwischen den genannten drei Texttypen flieBend; erst so entsteht ja der Eindruck eines gestalterischen Kontinuums. Eines jedoch ist allen in Helldunkel versammelten Wedichten « gemein: der strikte Verzicht auf metrische Strukturierung. Es handelt sich also durchweg um Texte in sungebundener Rede, denen gleichwohl spoetischer Qualitäten zugesprochen werden. Schlaf hat jetzt einen Sprechmodus in der Übergangszone von Vers und Prosa gefunden, den er als Ausdrucksregister - neben der Nutzung konventioneller Genres im Bereich der Narrativik und Dramatik - lebenslang beibehält. Im Gegensatz zu den meisten seiner Kollegen versteht er ihn freilich als prosaisches Vertextungsverfahren, obwohl die solcherart hergestellten Texte faktisch ein ganzes Arsenal rhetorischer Wirkmittel aufweisen. Offensichtlich glaubt Schlaf, parallel zu den formalisierten Gestaltungskonventionen der herkömmlichen Lyrik wie Metrum, Reim und strophische Gliederung spezifische Poetizitätskriterien prosaischen Ausdrucks entwickeln zu können, die er vor allem in den althebräischen Psalmen und in der antken dithyrambischen Dichtung verwirklicht sieht. Diese "Urgesänge “ ${ }^{155}$ transportieren seiner Ansicht nach ein natürliches Pathos, das noch nicht zu einem lyrischen Regelschematismus erstart ist. Um nun die Erneuerung der modernen Dichtkunst voranzutreiben, knüpft er an diese sursprünglichene und daher noch nicht formalisierten Textmuster an. Whitman wird ihm nicht zuletzt deshalb zum großen Vorbild, weil er die "Kraft und Energie der [...] Psalmisten und Propheten ${ }^{156}$ mit den Gegebenheiten der Moderne verbunden habe.

Kaum daß der Whitman-Einfluß in Schlafs literarischer Produktion formal und sprachlich erstmals klar sichtbare Spuren hinterlassen hat, verschwindet er freilich auch schon wieder aus seinem (Euvre. Da nach 1900 seine wästhetische Ambitionen« immer stärker hinter seiner »kulturpädagogischen Zielsetzung “ ${ }^{157}$ zurücktraten, verlegte sich der Autor in den ersten beiden Dekaden des 20. Jahrhunderts entweder auf die fast mit beliebigem Inhalt füllbare Romanform oder beschränkte sich ganz auf die Abfassung expositorischer Texte, in denen er seine naturwissenschaftlichen, kosmogonischen und kulturphilosophischen Spekulationen entwickelte. Erst in der

${ }^{155}$ Johannes Schlaf: Walt Whitman [1892], S. 980.

156 Ebd.

157 Dieter Kafitz: Johannes Schlaf - Weltanschauliche Totalität und Wirklichkeitsblindheit, S. 123. 
letzten Schaffensphase griff er das vor langer Zeit entwickelte Modell pathetischer Rede neuerlich auf und amalgamierte es mit Vertextungsweisen, welche zwischenzeitlich durch den Expressionismus popularisiert worden waren. ${ }^{158}$ Das Ergebnis sind eine Reihe von „Dichtungen« unterschiedlichster Länge: Gedichte in Prosa (1920), Das Gottlied (1922), Seele (1922), Deutschland (1925), Die Nacht der Planeten (1925), Die Mutter (1927) und Das Spiel der boben Limien (drei Fassungen: 1927, 1930, 1931). ${ }^{159}$ Die Reaktivierung eines aus poetologischen Überlegungen hervorgegangenen Ausdrucksmodus, der dem Aspekt künstlerischer Gestaltung - vor allem in wirkungsästhetischer Hinsicht ${ }^{160}$ - einen gewissen Eigenwert zugesteht und Texte nicht bloß als probate Vehikel einer mittlerweile zum umfassenden wissenschaftlichen Privatkosmos ausgebauten monistischen Theorie versteht, ${ }^{161}$ verweist dabei auf einen nochmaligen Wandel in Schlafs Literaturverständnis. 'Dichtung، erscheint nun als adäquateste und vollkommenste Form, die Schönheit der Natur ästhetisch zur Anschauung zu bringen. Auf diese Weise markieren die genannten Texte in gewisser Weise sogar eine Art Gipfelpunkt des Werks. Erst hier verwirklicht Schlaf im Grunde jene "poetry with cosmic and dynamic features of magnitude and limitlessness suitable to the human soul ${ }^{162}$, die er bei Whitman vorfand.

$\mathrm{Da}$ der deutsche Autor mit seiner späten "prosalyrischen Produktion « ${ }^{163}$ direkt an seine Experimente der neunziger Jahre anschloß, verdeutlicht der Umstand, daß sich zwei der insgesamt drei in dem Bändchen Gedichte in Prosa enthaltenen Texte schon in Helldunkel finden; ${ }^{164}$ sie wurden für die Neupublikation nur ganz geringfügig überarbeitet. Überhaupt hat Schlaf mehrfach bereits Publiziertes in späteren Werken wiederabdrucken lassen. Das erste der Gedichte in Prosa mit dem Titel Frei! etwa geht sieben Jahre später in den Band Das Spiel der hoben Linien ein. Diese pro-

${ }^{158}$ Vgl. hierzu Kapitel III/9.

159 Während Seele und die Gedichte in Prosa mit 13 und 16 Seiten vom Umfang her sehr bescheiden bleiben, erreichen Die Mutter (30 S.), Das Gottied (46 S.) und die erste Version des Spiels der bohen Linien (47 S.) schon eine beträchtliche Textdimension, die sich in der Nacht der Planeten $(67 \mathrm{~S}$.), in Deutschland (70 S.) und den beiden letzten Fassungen des Spiels der bohen Linien (105 und 159 S.) sukzessive zur Großform erweitert.

160 Am deutlichsten sichtbar wird dies in Deutschland, wo einer der insgesamt 14 römisch numerierten Abschnitte den Titel „Unsere alten vaterländischen Gesänge» trägt und auch in einem vorangestellten Hinweis auf die Appellstruktur von Texten im Zusammenhang der Befreiungskriege angespielt wird; vgl. Johannes Schlaf: Deutschland. Leipzig. Franz Peter Scholze Verlag o.J. [1925], S. 49 und 4.

161 Kafitz dagegen beklagt den »Vorrang der Theorier in Schlafs Spätwerk und sieht die Prosagedichte der zwanziger und frühen dreißiger Jahre nur als weine poetische Umsetzung kosmogonischer Spekulationen«; Dieter Kafitz: Johannes Schlaf - Weltanschauliche Totalität und Wirklichkeitsblindheit, S. 202.

162 Walt Whitman: Complete Poetry and Collected Prose, S. 661.

163 Johannes Schlaf: Aus meinem Leben, S. 60.

164 Vgl. Johannes Schlaf: Helldunkel. Gedichte, S. 82-84 (Auf der Düne) und 103-107 (Das Lied vom Tode). Kafitz ist dieser Zusammenhang offenkundig entgangen. 
blemlose Translozierbarkeit ist ein deutlicher Beleg dafür, daß die Sprachgebung der späten Texte sich nicht nennenswert von den früheren freien Rhythmen und Dichtungen in Prosaform unterscheidet. Hier wie dort folgt Schlaf den Modellen spoetischer Prosar und hymnischer Dithyrambik aus Bibel und antiker Dichtung, wie er sie bei Whitman wiederzufinden meint.

Was die Publikationen der zwanziger und frühen dreißiger Jahre gattungstypologisch bedeutsam erscheinen läßt, ist in erster Linie ihre interne Strukturierung. Durchweg nämlich sind diese »Dichtungen in zahlreiche einzelne Textbestandteile gegliedert. Tragen diese Segmente Titel (wie in Die Nacbt der Planeten) oder Ziffern (wie der in Bd. 2 der Ausgewählten Werke enthaltene Text Stella Maris), werden sie in sich weiter unterteilt. Schon im Band In Dingsda hatte Schlaf mehrere Texte der Sammlung durch Asterisken in kleinere Abschnitte zerfallen lassen. ${ }^{165}$ Diese Verfahrensweise übernahm er dann auch in Frübling und den späteren Publikationen. In allen Fällen entstehen dadurch strophenähnliche Segmente, welche die Texte in gewisser Weise lyrisch wirken lassen, ihnen zugleich aber auch das Ansehen geben, hier wären mehrere kurze Prosagedichte zu einem größeren Komplex zusammengeschlossen. ${ }^{166}$ Schlafs Gestaltungstechnik unterläuft geschickt den traditionellen Gegensatz zwischen literarischen Kurz- und Langformen und trägt zusätzlich dazu bei, Vers und Prosa auch auf der Ebene des Textumfangs miteinander zu amalgamieren. (Vor allem Autoren im Umkreis des Expressionismus haben dieses Prinzip fruchtbar zu machen versucht.) Allerdings weicht sie faktisch auch den Gattungsstatus der Ausdrucksform Prosagedicht auf, geht dieser doch mit dem Merkmal des kurzen, an den Vertextungsnormen der Lyrik orientierten Umfangs das entscheidende Textsortenmerkmal verloren, das sie zuverlässig von den diversen Genres der narrativen Prosa unterscheidet. Schlaf geht es freilich gar nicht um die Etablierung eines neuen literarischen Gestaltungsmusters. Er nutzt die bestehenden textuellen Spielarten im Übergangsbereich zwischen Vers und Prosa, darunter auch das Prosagedicht, um eine nachhaltige Ausweitung der sprachlichen Ausdrucksmodi zu erreichen: Zum einen soll die in seinen Augen unsinnige diskursive Grenzziehung zwischen sPoesier und Prosa fallen, zum anderen soll aber auch die mit dieser Leitdifferenz auf intrikate Weise gekoppelte gattungskonstitutive Funktion des Textumfangs verabschiedet werden.

${ }^{165}$ Vor Schlaf hat bereits Liliencron diese Technik in mehreren seiner kürzeren Prosatexte verwendet. Riedel ebnet den gattungstransgressiven Charakter des nicht zufallig ohne Genrebezeichnung erschienenen Bandes Frübling mit seinen insgesamt 14 betitelten, durch einen fortlaufenden Handlungsfaden zusammengehaltenen Textabschnitten ein, wenn er die Sammlung kurzerhand „Novelle» nennt; Wolfgang Riedel: "Homo Natura«. Literarische Anthropologie um 1900, S. 120, Anm. 162, und S. 123, Anm. 168.

166

Daher konnte Bölsche die äußerlich klar als Prosa ausgewiesenen Texte von In Dingsda zugleich als "Skizzen« und als "Lyrik ohne Strophen« bezeichnen; Wilhelm Bölsche: Johannes Schlafs In Dingsda. In: Freie Bühne für modernes Leben 2 (1891), S. 986. 
Welch große Rolle Fragen der Länge und Binnengliederung eines Textes als zentrale Parameter seiner Gattungszugehörigkeit in den ästhetischen Debatten der Zeit spielten, kann beispielhaft die Rezeption von Pierre Louys' Chansons de Bilitis (1894) in Deutschland verdeutlichen. Dieses Werk bietet sich - je nach Blickwinkel des Betrachters - entweder als "Roman« oder als eine Art Prosagedichtzyklus, bestehend aus "100 Liedern von nur je 4 Strophen ${ }^{167}$, dar. Eine derartige Strukturierungsweise erschien den Zeitgenossen vor allem deshalb verlockend, weil damit der vermeintlich unkünstlerische Charakter der narrativen Erzählprosa überwunden werden konnte. So schreibt etwa Dehmel begeistert an Henri Albert: "Vor allem ist mit diesem Buche ein großer Schritt vorwärts gethan auf dem Wege der Composition! das byrisch componirte Welt-und-Seelenbild kann den alten Roman, dies fürchterliche Zwittermachwerk, erst zum Kunstwerk entwickeln ${ }^{168}$. Ganz ähnlich heißt es in einem Brief an Arno Holz vom 13. November 1895: "Nur die bropsychologische Composition des Weltbilds kann aus dieser Gattung ein reines, innerlich und äußerlich geschlossenes Kunstwerk werden lassen. Sie wissen, wie hoch ich deshalb, schon blos technisch, das vierte Buch Zarathustra verehre. ${ }^{169}$ Beide Stellungnahmen verdeutlichen, daß das Prosagedicht, sobald es eine bestimmte Umfangsgrenze überschreitet, zwangsläufig vom Deutungssog traditioneller Gattungsmuster erfaßt wird. Entweder gerät es in das Spannungsfeld der narrativen Erzählprosa und amalgamiert sich mit den historisch schon bestehenden Spielarten der spoetischen Prosac, oder es nähert sich - wie im Spätwerk Schlafs - den lyrischen Großformen an.

In internationaler Perspektive sind die deutschen Ansätze, literarische Antworten auf die ideologische Herausforderung durch den populären naturwissenschaftlichen Monismus zu finden, singulär. Weder in Frankreich noch in den anderen europäischen Ländern begegnen künstlerische Entgrenzungsversuche im Übergangsbereich von sgebundener< und sungebundener` Rede, die sich als Rückkoppelungsphänomene auf neuere naturwissenschaftliche Theorien deuten lassen. Allerdings erweist sich der in Deutschland zu beobachtende Anschluß des Prosagedichts an außerästhetische Diskurse im Kontext der Gattungsentwicklung als überaus ambivalent: Einerseits avanciert die Textform dadurch zum - zumindest auf den ersten Blick strahl-

${ }^{167}$ Richard Dehmel an Amo Holz, 13.11.1895; Richard Dehmel: Ausgewählte Briefe aus den Jahren 1883 bis 1902 [ $=$ Bd. 1]. Berlin: S. Fischer 1923, S. 222. Der Begriff $» R o m a n \lll$ als Beschreibungsterminus für das Werk findet sich auch in einem Brief an Henri Albert vom selben Tag, vgl. Eine deutsch-französische Brieffreundschaft. Richard Dehmel - Henri Al168 bert. Briefwechsel 1893-1898, S. 200.

${ }^{169}$ Richard Dehmel: Ausgewählte Briefe aus den Jahren 1883 bis 1902, S. 223. Dehmel greift mit dieser Einschätzung auf das alte Diktum Schillers zurück, der den »Romanschreiberı als "Halbbruder« des Dichters" abqualifiziert hatte; Friedrich Schiller: Sämtliche Werke, Bd. 5, S. 741. 
kräftigen - Inszenierungsort von Transgressivität; indem andererseits aber aufs Ganze gesehen die Subversion der dichotomischen Verfaßtheit des Literatursystems und die Überwindung der sklassischen Gattungstrias nur einen Aspekt der intendierten Grenzüberschreitungen bilden, verkümmert die damit verbundene literarische Innovation zu einer relativ unbedeutenden Arabeske in einem generell durch Transitorik gekennzeichneten größeren Geschehenszusammenhang. Als besonders problematisch erweist sich in diesem Kontext die Rückführung von Ästhetik auf «Natur, weil dadurch künstlerische Phänomene ontologisiert werden, was im Endeffekt genau jener dogmatischen Verfaßtheit des Literatursystems in die Hände arbeitet, gegen die das Prosagedicht ursprünglich konzipiert worden ist. Abermals zeigt sich hier, wie sehr sich die deutsche Gattungsentwicklung von den Voraussetzungen im Mutterland des poème en prose abgekoppelt hat und wie unterschiedlich das Genrekonzept in beiden Kulturen funktioniert. 
